\title{
Discovery of Pathogenicity Genes in the Crucifer Anthracnose Fungus Colletotrichum higginsianum, Using Random Insertional Mutagenesis
}

\author{
Aurélie Huser, Hiroyuki Takahara, Wolfgang Schmalenbach, and Richard O'Connell \\ Max-Planck-Institute for Plant Breeding Research, Department of Plant-Microbe Interactions,D-50829 Köln, Germany
}

Submitted 21 August 2008. Accepted 26 October 2008.

\begin{abstract}
Agrobacterium tumefaciens-mediated transformation (ATMT) was used for random insertional mutagenesis to identify pathogenicity genes in the hemibiotrophic fungus Colletotrichum higginsianum. A high-throughput primary infection assay on Arabidopsis thaliana seedlings allowed the rapid screening of $\mathbf{8 , 8 5 0}$ transformants. Forty mutants showing reproducible pathogenicity defects on Arabidopsis and Brassica plants were obtained, and their infection phenotypes were characterized microscopically. Six mutants were impaired in appressorial melanization, fifteen had reduced penetration ability, 14 induced host papillae or hypersensitive cell death, and five were affected in the transition from biotrophy to necrotrophy. Southern blot analysis showed $58 \%$ of the transformants had single-site T-DNA integrations. Right-border flanking sequences were recovered from 12 mutants by inverse polymerase chain reaction (PCR) or thermal asymmetric interlaced PCR and were used to isolate the tagged genes from a genomic library. The putative pathogenicity genes encoded homologs of a major facilitator superfamily phosphate transporter, importin- $\beta 2$, ornithine decarboxylase, $\beta$-1,3(4)-glucanase, ATP-binding endoribonuclease, carbamoyl-phosphate synthetase, and the polyprotein precursor of $\mathrm{N}$-acetylglutamate kinase and $\mathrm{N}$ acetylglutamyl-phosphate reductase. Six further loci were homologous to proteins of unknown function. None of these genes were previously implicated in the pathogenicity of any Colletotrichum species. The results demonstrate that ATMT is an effective tool for gene discovery in this model pathogen.
\end{abstract}

Colletotrichum higginsianum causes anthracnose disease on a wide range of cruciferous plants, including agronomically important species, such as members of genera Brassica and Raphanus as well as the model plant Arabidopsis thaliana (Narusaka et al. 2004; O'Connell et al. 2004). To invade host tissues, this hemibiotrophic fungus sequentially elaborates a series of specialized infection structures. Following attachment to the plant surface, conidia germinate to form dome-shaped, melanized appressoria that pierce the cuticle and cell wall directly, by means of a narrow penetration peg. Swollen primary hyphae then invade living epidermal cells and invaginate the host plasma membrane, like the haustoria of obligate biotrophs. Both the biotrophic phase and the specialized primary hyphae

Corresponding author: Richard J. O'Connell;

E-mail: oconnel@mpiz-koeln.mpg.de

* The $e$-Xtra logo stands for "electronic extra" and indicates that three supplemental figures are published online. of $C$. higginsianum are entirely restricted to the first infected epidermal cell, in contrast to other hemibiotrophic Colletotrichum species (O'Connell et al. 2004). Thereafter, the fungus switches to a necrotrophic mode of growth, associated with production of thin secondary hyphae which ramify within and between host cells and kill host cells ahead of infection.

The $C$. higginsianum- $A$. thaliana pathosystem provides an attractive model for the molecular dissection of plant-fungal interactions. In addition to its interesting hemibiotrophic lifestyle and developmental transitions, $C$. higginsianum can be cultured axenically and can be stably transformed, allowing the analysis of gene function by random mutagenesis and targeted disruption (O'Connell et al. 2004). Moreover, in contrast to most other Colletotrichum species, the plant host is also amenable to molecular manipulation, and extensive genomic resources and genetic tools are available for analyzing resistant and susceptible responses. However, although some candidate genes have been identified from the sequence analysis of stage-specific cDNA libraries (Kleemann et al. 2008), no molecular determinants of pathogenicity or virulence have, so far, been isolated from $C$. higginsianum.

Random insertional mutagenesis is a powerful approach for gene discovery in fungi (Kahmann and Basse 1999) and has been successfully used to isolate pathogenicity genes from $C$. lagenarium, $C$. lindemuthianum and C. graminicola (Dufresne et al. 1998; Kimura et al. 2001; Perpetua et al. 1996; Takano et al. 1995; Tanaka et al. 2007; Thon et al. 2000). Following the first report of Agrobacterium tumefaciens-mediated transformation (ATMT) of filamentous fungi in 1998 (de Groot et al. 1998), it has become established as the method of choice, not only for random insertional mutagenesis but also for targeted gene disruption by homologous recombination (Michielse et al. 2005). The principal advantages of ATMT over previous mutational methods such as restriction enzyme-mediated integration (REMI) are the high efficiency of transformation, the frequency of single-copy integrations, the ability to transform intact cells rather than protoplasts, and the creation of fewer untagged mutations (Michielse et al. 2005; Weld et al. 2006). Several recent studies have questioned the randomness of $\mathrm{T}$ DNA integration into recipient fungal genomes (Choi et al. 2007; Li et al. 2007; Meng et al. 2007). Nevertheless, ATMT has been successfully exploited for large-scale forward genetic screens in several pathogenic species, including Magnaporthe grisea, Cryptococcus neoformans, C. lagenarium, and Leptosphaeria maculans (Betts et al. 2007; Blaise et al. 2007; Jeon et al. 2007; Walton et al. 2005; Tsuji et al. 2003).

We have previously shown that $C$. higginsianum can be efficiently transformed by ATMT (O'Connell et al. 2004). In the present study, we report the first application of ATMT for 
insertional mutagenesis of $C$. higginsianum and describe a sensitive, high-throughput infection assay to detect mutants affected in their pathogenicity on Arabidopsis. A collection of 40 mutants impaired at different stages of their development was obtained, and their infection phenotypes were characterized microscopically. Sequence analysis of the tagged genes led to the isolation of 14 putative pathogenicity genes with potential roles in appressorial pigmentation, penetration, avoidance or suppression of host defenses, nutrition, and the switch from biotrophy to necrotrophy. None of these genes were previously implicated in the pathogenicity of any Colletotrichum species. Overall, our findings indicate that insertional mutagenesis by ATMT will be a valuable tool for the genome-wide analysis of gene function in this important model pathogen.

\section{RESULTS}

\section{ATMT of $C$. higginsianum.}

Two binary vectors were used for fungal transformation, namely, pBIN-GFP-hph and pBIG2RHPH2 (O'Connell et al. 2004; Tsuji et al. 2003), but the efficiency of transformation did not differ significantly. In 25 independent transformation experiments, the number of hygromycin-resistant transformant colonies obtained from $10^{6}$ spores varied from 75 to 125 (average $=102$ ). In all, 8,850 transformants were generated, of which 5,100 had pBIN-GFP-hph insertions and 3,750 had pBIG2RHPH2 insertions. Southern blot analysis (Fig. 1A and B) revealed that of 55 randomly selected transformants, 32 (58\%) had a single T-DNA insertion, 16 (29\%) had two inser- tions, and seven (12\%) had three or more insertions (Fig. 1C). Among 12 pathogenicity mutants for which T-DNA right-border sequences were obtained, 10 contained two T-DNA copies, and of these, seven were tandem insertions at a single site in the genome (Fig. 1D), arranged in direct repeat (head-to-tail) orientation. In addition, one mutant (path-35) contained a singlesite insertion of three T-DNA repeats. The transformants appeared to be mitotically stable, because monoconidial cultures from five randomly selected transformants retained hygromycin $B$ resistance after subculturing five times on potato dextrose agar (PDA) without hygromycin selection.

\section{Pathogenicity mutant screen.}

After subjecting 8,850 transformants to two rounds of testing in a primary mutant screen on Arabidopsis seedlings, 265 (3\%) consistently produced either no visible symptoms or reduced symptoms as compared with the wild type (Fig. 2). Of these, 40 transformants $(0.45 \%)$ were verified as pathogenicity mutants after two rounds of testing in a secondary screen on mature Arabidopsis plants. Such mutants consistently produced either no visible symptoms or greatly reduced symptoms, e.g., scattered necrotic flecks or small lesions restricted to the oldest rosette leaves (Fig. 2). In contrast, the C. higginsianum wild-type strain extensively macerated host tissues, and plants were completely collapsed at 7 days after inoculation (dai) (Fig. 2). The altered pathogenicity phenotypes observed in these mutants were not specific to the interaction with Arabidopsis, since, when inoculated onto seedlings of a highly susceptible brassica host (B. napus biennis),
A

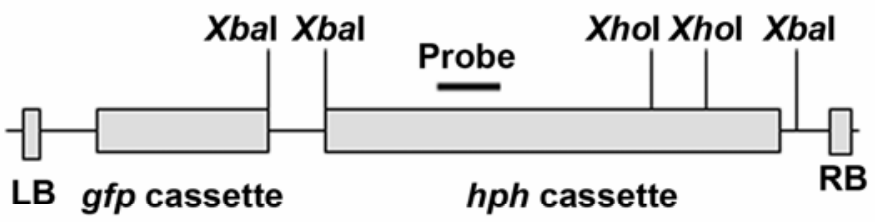

B
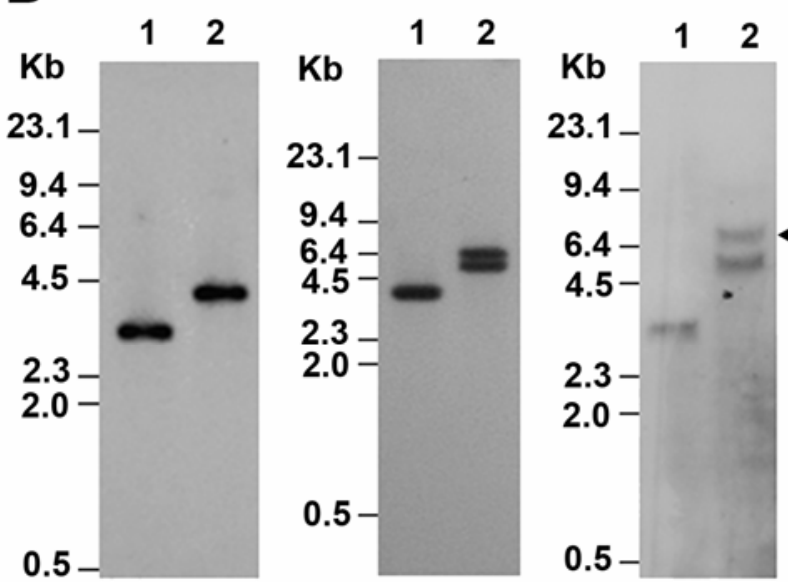

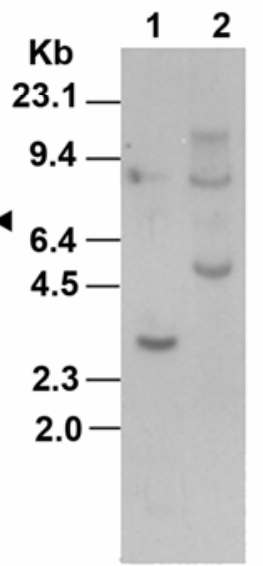

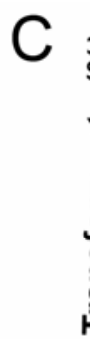

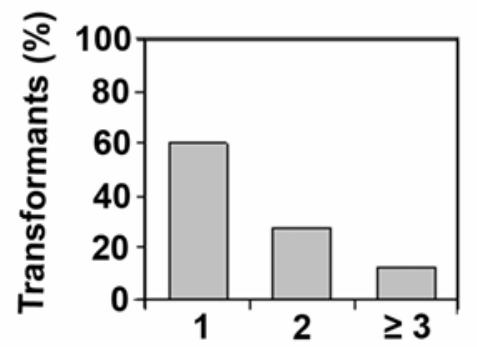

Number of T-DNA insertions
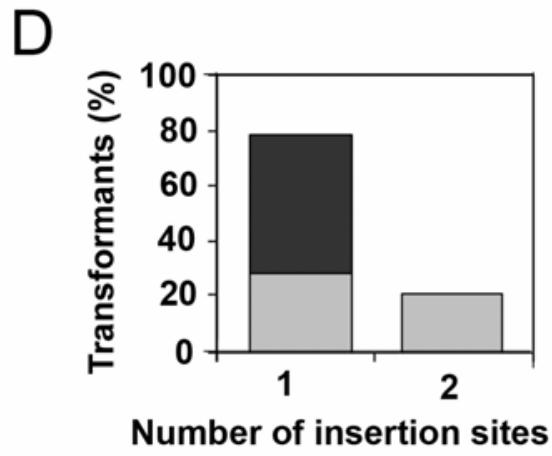

Fig. 1. Analysis of T-DNA copy number in Colletotrichum higginsianum transformants. A, Physical map of transformation vector pBIN-GFP-hph containing the green fluorescent protein ( $g f p)$ and hygromycin resistance $(h p h)$ gene cassettes between the left (LB) and right (RB) borders (O'Connell et al. 2004). Po-

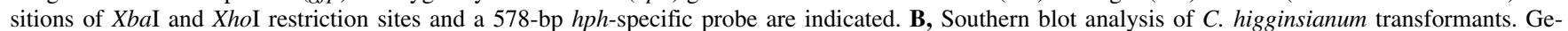
nomic DNA from four representative p-BIN-GFP-hph transformants was digested with either XbaI (lane 1) or XhoI (lane 2) and was hybridized with the digoxigenin-labeled $h p h$ probe. XbaI cuts the T-DNA on either side of the probe, so that the size of the hybridizing bands reveals any large RB truncations of the T-DNA. XhoI cuts the T-DNA on one side of the probe, so that the number of hybridizing bands corresponds to the number of T-DNA insertions. The four panels show (from left to right) examples of transformants with a single insertion, two independent insertions, two T-DNA tandemly inserted at a single site, and three independent insertions. In the case of tandem insertions, a fragment of $6.6 \mathrm{~kb}$ was obtained upon digestion with XhoI (arrowhead). Molecular size is indicated in kilobases (kb). C, Number of T-DNA insertions in 55 randomly selected transformants of $C$. higginsianum, as determined by Southern blot analysis. D, Number of T-DNA insertion sites in 12 pathogenicity mutants, as determined by sequencing genomic DNA flanking the T-DNA obtained by thermal asymmetric interlaced-polymerase chain reaction (PCR) or inverse PCR. Black bar indicates tandem insertions at a single site. 
they produced very reduced or no visible symptoms. In contrast, Brassica cotyledons were completely macerated by the wild-type strain at 7 dai (Fig. 2).

It was not possible to test 53 of the 265 putative pathogenicity mutants in the secondary screen because they produced insufficient spores for spray-inoculation at the required spore concentration. Such candidates appeared to be defective in conidiation rather than vegetative growth but were not characterized further. Some mutants were also eliminated from the secondary screen because their vegetative growth on rich media was severely reduced, as compared with the wild type. Among the 40 verified pathogenicity mutants emerging from the secondary screen, four (path-19, path-20, path-21, and path-35) were putative auxotrophs, since they grew poorly on minimal medium ( $\geq 69 \%$ growth reduction) but showed normal growth on rich media (Table 1, Supplementary Figs. 1 and 2). Two of these (path-19 and path-35) were subsequently found to be arginine auxotrophs, but the nutritional defects in the other two (path20 and path-21) were not determined.

\section{Infection phenotypes of the pathogenicity mutants.}

Light microscopy was used to determine at which stage of host infection the development of the mutants was impaired. Assessments included appressorium morphology (size, shape, melanization, penetration pore formation), appressorium penetration ability (living host epidermis, dead leaf tissue or cello- phane), ability to form biotrophic primary hyphae and necrotrophic secondary hyphae in planta, and induction of host defense responses such as callose deposition and hypersensitive cell death (HR). Based on their infection phenotypes, the 40 pathogenicity mutants were classified into four groups: melanindeficiency, impaired penetration, induction of host defense responses, and failure to enter the necrotrophic phase (Table 1).

Melanin-deficient mutants. Six pathogenicity mutants produced spores that germinated normally and differentiated appressoria, but the cell walls of the latter were either not melanized (path-1, path-4, path-5) or very weakly melanized (path2 , path-3, and path-6), unlike the darkly pigmented wild-type strain (Fig. 3). With the exception of path-6, appressoria of these mutants were completely unable to penetrate living host epidermal cells, ethanol-killed leaves, or cellophane membranes. Only $12 \%$ of path-6 appressoria penetrated living host cells (compared with $77 \%$ in the wild type), but these went on to develop normal primary and secondary hyphae (Table 1). Although unable to penetrate intact leaf surfaces, all the mutants formed necrotic lesions similar to the wild type on wounded tissue except path-5, which produced smaller lesions (Fig. 4). Thus, the melanin mutants were capable of invasive growth in planta if the initial penetration step was circumvented.

Host-penetration mutants. A total of 15 pathogenicity mutants (path-7 to path-21) produced fully melanized appressoria with visible penetration pores but either completely failed to

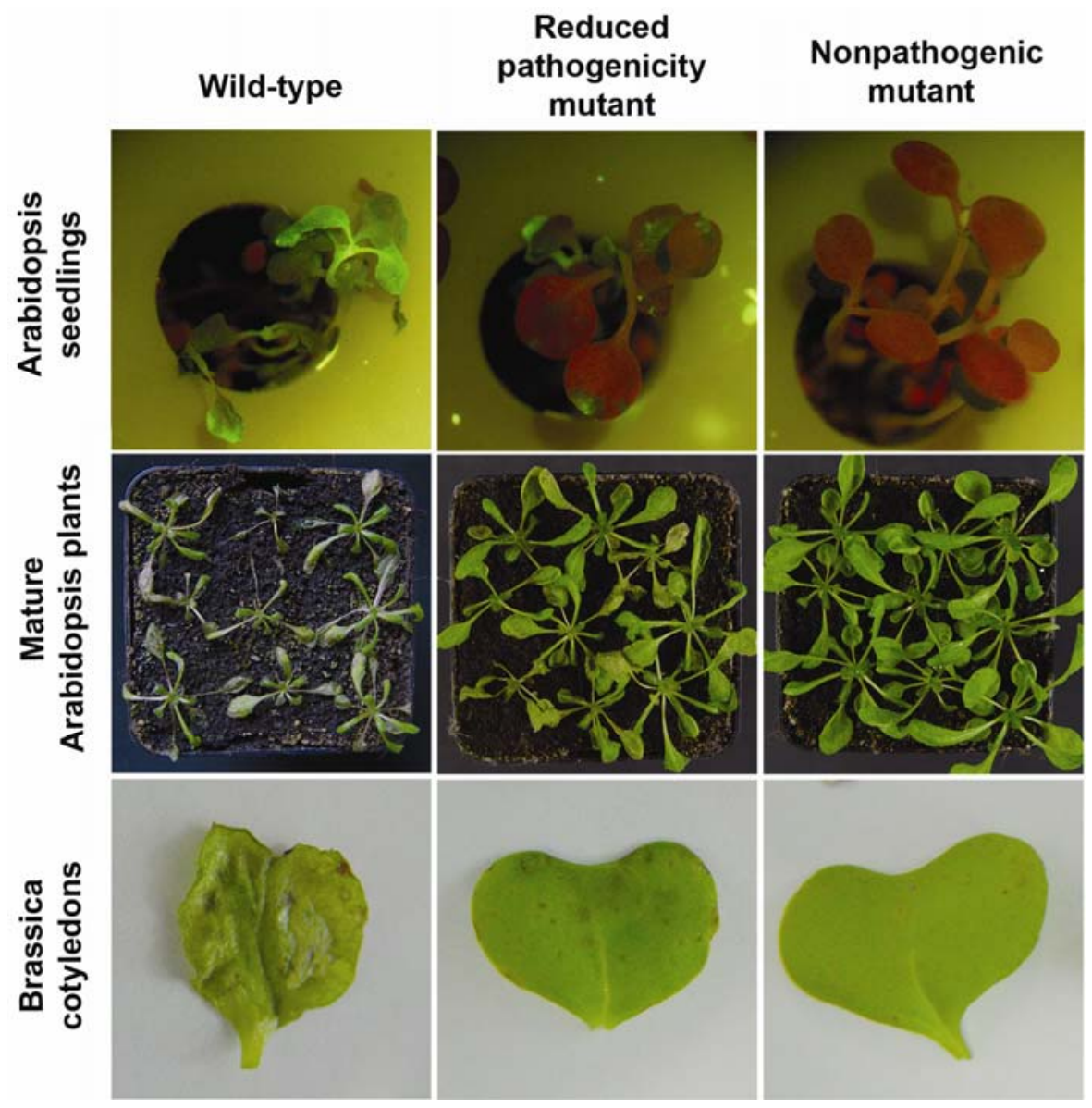

Fig. 2. Pathogenicity assays used to select Colletotrichum higginsianum mutants. Top row: In a primary screen, Arabidopsis seedlings were droplet-inoculated with spore suspension of $C$. higginsianum transformants, and symptoms were scored at 7 days after inoculation (dai) by fluorescence microscopy. Dead tissue autofluoresced green while healthy tissue autofluoresced red. Seedlings inoculated with the wild-type strain collapsed and showed extensive green fluorescence. Transformants causing small green fluorescent necrotic lesions or no visible symptoms were selected as putative pathogenicity mutants. Middle row: In a secondary screen, mature Arabidopsis plants were spray-inoculated with transformant spore suspension and were examined for symptoms 7 dai. The wild-type strain caused extensive necrosis and maceration. Transformants producing limited necrotic lesions were considered reduced pathogenicity mutants, and those causing no symptoms were considered nonpathogenic. Bottom row: Pathogenicity assay on seedlings of Brassica napus biennis. The wild-type strain completely macerated cotyledons, whereas pathogenicity mutants produced scattered brown necrotic flecks or no visible symptoms. 
penetrate living host cells or penetrated with lower frequency than the wild type (Table 1). Microscopic inspection of the epidermal cells underlying appressoria of these mutants revealed that neither callose papillae nor $\mathrm{H}_{2} \mathrm{O}_{2}$ accumulation occurred more frequently than with wild-type appressoria (Table 1). This suggests their failure to penetrate host tissue resulted from a defect in appressorial function rather than induction of host defense responses. Consistent with this view, seven mutants were also unable to penetrate either inert cellophane membranes
(Table 1; Fig. 5A) or ethanol-killed leaf tissue (Fig. 5B). However, eight other mutants could penetrate both cellophane and dead leaf tissue, although less efficiently than the wild type in most cases (Table 1). With the exception of path-12, all penetration mutants retained invasive growth ability because they produced necrotic lesions similar to the wild type on wounded leaf tissue (Fig. 4).

Mutants inducing host defense responses. A total of 14 pathogenicity mutants (path-22 to path-35) formed appressoria that

Table 1. Summary of Colletotrichum higginsianum pathogenicity mutant phenotypes

\begin{tabular}{|c|c|c|c|c|c|c|}
\hline Mutant IDa & $\begin{array}{c}\text { Growth on } \\
\text { minimal mediumb }\end{array}$ & $\begin{array}{l}\text { Appressorium } \\
\text { melanization }^{c}\end{array}$ & $\begin{array}{l}\text { Penetration of } \\
\text { epidermis }^{\mathrm{d}}\end{array}$ & $\begin{array}{l}\text { Penetration of } \\
\text { cellophane }^{\mathrm{e}}\end{array}$ & $\begin{array}{l}\text { Secondary } \\
\text { hyphae }^{f}\end{array}$ & $\begin{array}{l}\text { Induction of host } \\
\text { defense responses }\end{array}$ \\
\hline Wild-type & + & ++ & +++ & +++ & ++ & Rare P \\
\hline \multicolumn{7}{|c|}{ Melanin-deficient mutants } \\
\hline path-1* & + & - & - & - & - & - \\
\hline path-2* & + & + & - & - & - & - \\
\hline path-3* & + & + & - & - & - & - \\
\hline path-4* & + & - & - & - & - & - \\
\hline path $-5 *$ & + & - & - & - & - & - \\
\hline path-6* & + & + & + & - & + & - \\
\hline \multicolumn{7}{|c|}{ Host penetration mutants } \\
\hline path-7* & + & ++ & + & +++ & + & - \\
\hline path-8* & + & ++ & - & - & - & - \\
\hline path-9* & + & ++ & + & - & + & - \\
\hline path $-10 *$ & + & ++ & + & ++ & - & - \\
\hline path-11* & + & ++ & - & ++ & - & - \\
\hline path-12* & + & ++ & + & ++ & - & - \\
\hline path-13* & + & ++ & + & ++ & - & - \\
\hline path-14* & + & ++ & + & - & - & - \\
\hline path $-15^{*}$ & + & ++ & - & - & - & - \\
\hline path-16* & + & ++ & + & - & - & - \\
\hline path $-17 *$ & + & ++ & - & - & - & - \\
\hline path-18* & + & ++ & + & - & - & - \\
\hline path-19* & - & ++ & + & + & - & - \\
\hline path-20* & - & ++ & + & + & + & - \\
\hline path-21* & - & ++ & + & + & + & - \\
\hline \multicolumn{7}{|c|}{ Mutants inducing host defense responses } \\
\hline path-22* & + & ++ & +++ & +++ & + & $\mathrm{P}$ and $\mathrm{HR}$ \\
\hline path-23* & + & ++ & - & + & - & Large $\mathrm{P}$ \\
\hline path-24* & + & ++ & ++ & ++ & - & HR \\
\hline path-25 & + & + & +++ & +++ & + & HR \\
\hline path-26 & + & ++ & +++ & +++ & + & HR \\
\hline path-27 & + & + & ++ & +++ & + & $\mathrm{P}$ and $\mathrm{HR}$ \\
\hline path-28 & + & + & +++ & +++ & + & $\mathrm{P}$ and $\mathrm{HR}$ \\
\hline path-29* & + & ++ & ++ & +++ & + & HR \\
\hline path-30* & + & ++ & +++ & +++ & - & HR \\
\hline path-31 & + & ++ & +++ & +++ & - & HR \\
\hline path-32* & + & ++ & + & +++ & - & $\mathrm{P}$ \\
\hline path-33* & + & ++ & +++ & +++ & + & HR \\
\hline path-34* & + & ++ & ++ & +++ & - & HR \\
\hline path-35* & - & ++ & + & + & - & $\mathrm{P}$ \\
\hline \multicolumn{7}{|c|}{ Mutants impaired in switch to necrotrophy } \\
\hline path-36* & + & ++ & +++ & +++ & + & - \\
\hline path-37* & + & ++ & +++ & +++ & - & - \\
\hline path-38* & + & ++ & +++ & +++ & - & - \\
\hline path-39* & + & ++ & +++ & +++ & - & - \\
\hline path-40 & + & ++ & +++ & +++ & + & - \\
\hline
\end{tabular}

${ }^{a}$ Asterisks (*) indicate mutants causing no symptoms or very reduced symptoms, with necrosis limited to oldest rosette leaves.

${ }^{\mathrm{b}}$ Radial growth rate was measured after 4 days on Czapek-Dox minimal medium. + indicates wild-type growth rate and - indicates reduced growth rate $(\geq 69 \%)$.

${ }^{\mathrm{c}}$ Melanization was assessed at 3 days after inoculation (dai). - indicates albino appressoria, + indicates weakly melanized appressoria, and ++ indicates darkly melanized appressoria similar to wild type.

${ }^{\mathrm{d}}$ Penetration was quantified at 3 dai as a percentage of appressoria producing a visible penetration peg or hypha in the underlying epidermal cell. - indictaes $<10 \%$ penetration; + indicates 11 to $35 \%$ penetration; ++ indicates 36 to $59 \%$ penetration; and +++ indicates $>60 \%$ penetration similar to wild type.

e Penetration of cellophane was quantified after $36 \mathrm{~h}$ as a percentage of appressoria that had produced a visible hypha inside the cellophane. - indicates $<10 \%$ penetration, + indicates 11 to $35 \%$ penetration, ++ indicates 36 to $70 \%$ penetration; and +++ indicates $>70 \%$ penetration similar to wild type.

${ }^{\mathrm{f}}$ Entry into the necrotrophic phase was quantified at 4 dai as a percentage of appressoria giving rise to secondary hyphae. - indicates < $30 \%$ secondary hyphae, + indicates 31 to $59 \%$ secondary hyphae, and ++ indicates $>60 \%$ secondary hyphae similar to wild type.

$\mathrm{g}$ Two host defense responses were quantified: deposition of callose papillae (assessed by aniline blue staining) and induction of hypersensitive cell death (HR) (assessed by detecting $\mathrm{H}_{2} \mathrm{O}_{2}$ accumulation in dead cells with diaminobenzidine). The percentage of appressoria inducing callose deposition or HR in underlying epidermal cells was determined at 3 dai. Mutants inducing significantly more papillae or $\mathrm{HR}$ than the wildtype $(P<0.05)$ are indicated by $\mathrm{P}$ or $\mathrm{HR}$, respectively. In all quantitative assays, at least 100 appressoria per mutant were counted in three independent experiments. 


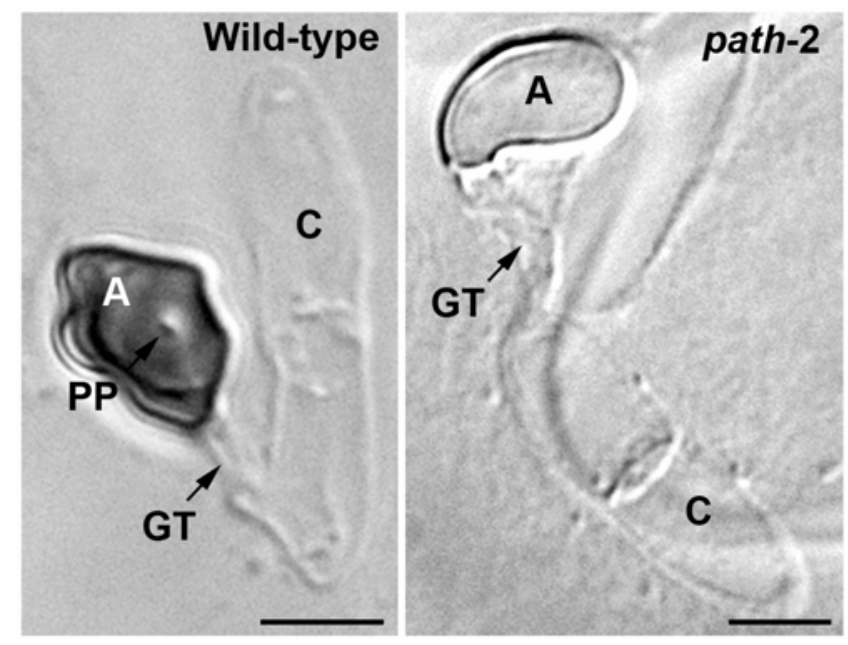

Fig. 3. Appressorial morphology of a melanin-deficient Colletotrichum higginsianum mutant. Arabidopsis plants were inoculated with spore suspension of the $C$. higginsianum wild-type strain and melanin-deficient mutant path-2. After 2 days, leaf tissue was cleared and viewed with differential interference contrast microscopy. Both mutant and wild-type conidia (C) germinated to form germ tubes (GT) and appressoria (A). However, the wild-type appressorium is darkly melanized and contains a basal penetration pore (PP), whereas the appressorium of path-2 is weakly melanized and has no visible penetration pore. Scale bars $=5 \mu \mathrm{m}$
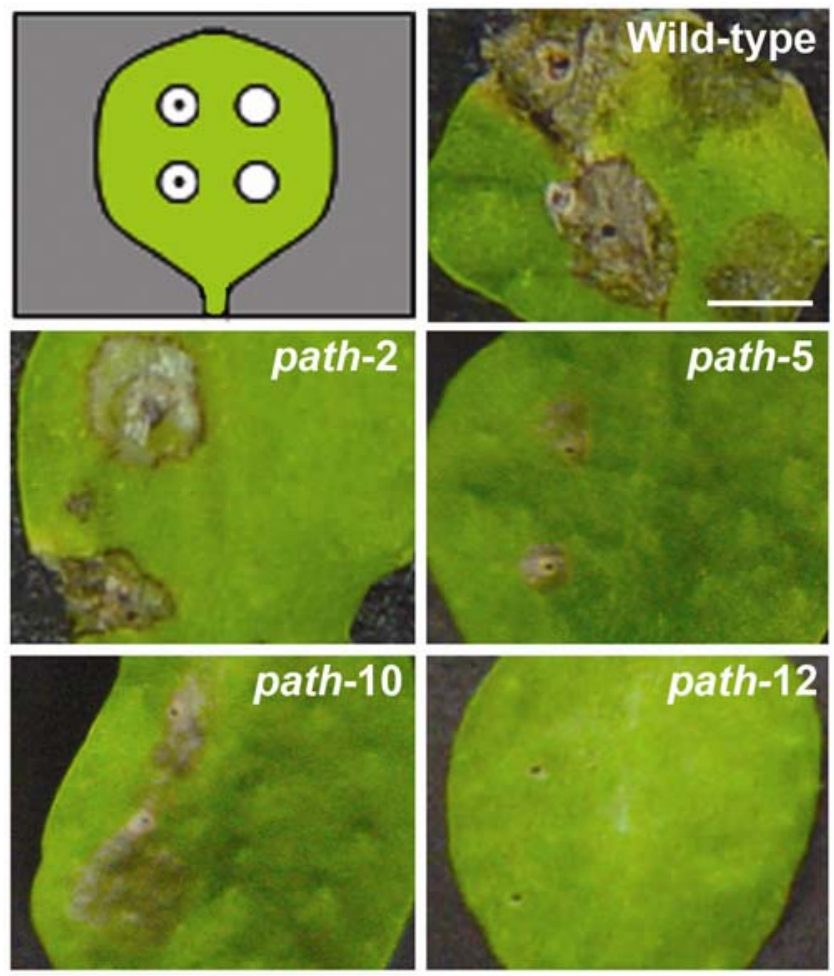

Fig. 4. Invasive growth assay for melanin-deficient and penetration mutants. Arabidopsis leaves were droplet-inoculated with Colletotrichum higginsianum conidial suspension. Top left panel: two sites on the left half of each leaf were wounded with a fine sterile needle prior to inoculation (indicated by a circle with a dot), whereas two inoculation sites on the right half were not wounded (indicated by an empty circle). After 7 days, the wild-type strain caused brown necrotic lesions on both wounded and intact tissue. Two melanin-deficient mutants (path-2 and path-5) and penetration mutant path-10 caused no symptoms on intact tissue but were capable of invasive growth when inoculated onto a wound, causing necrotic lesions similar to or smaller than the wild type. Penetration mutant path-12 lacked invasive growth ability, because it failed to produce symptoms on both wounded and intact tissue. induced host defense responses with higher frequency than the wild-type strain, e.g., deposition of callose papillae at fungal penetration sites, HR cell death, or a combination of both (Table 1).

The frequency with which appressoria induced HR in underlying epidermal cells was quantified at 3 dai by staining leaf tissue with 3,3-diaminobenzidine (DAB) to detect $\mathrm{H}_{2} \mathrm{O}_{2}$ accumulation in the dead host cells. The efficiency of appressorial penetration was also scored according to whether a penetration peg or primary hypha was visible within the host cell. Figure 6A shows representative data for the $C$. higginsianum wildtype strain and four selected mutants. Appressoria of all four mutants induced HR in epidermal cells significantly more frequently than the wild type $(P<0.05)$. In addition, the penetration efficiency of path-24 and path-29 was significantly less than the wild type $(P<0.05)$, and thus, appressoria of these mutants frequently induced HR without producing a visible hypha inside the affected cell. In contrast, path-31 and path-34 were unaffected in their penetration efficiency, but their development became arrested at the penetration peg or primary hypha stage, and even after 7 days, they had not grown beyond one epidermal cell. In seven other mutants, a small proportion of appressoria did not induce HR and successfully developed to the point of forming necrotrophic secondary hyphae, especially on older rosette leaves, but they produced less severe necrotic symptoms than the wild type (Table 1). In most cases,

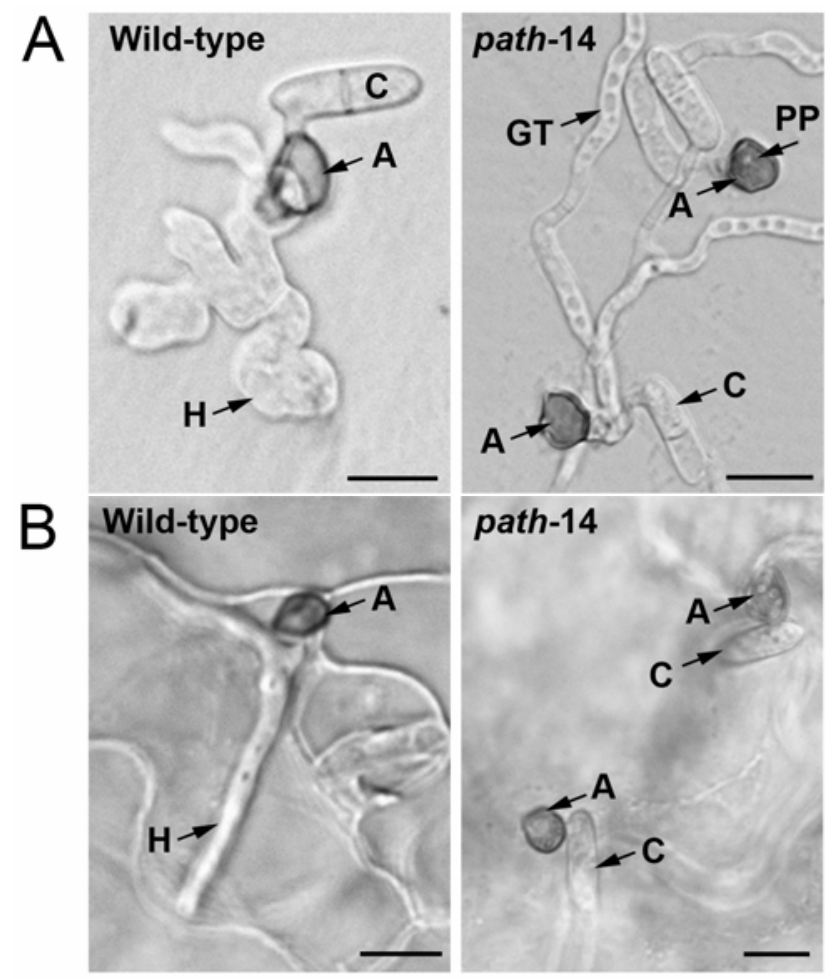

Fig. 5. Appressorial penetration of inert substrata, i.e., cellophane and dead leaf tissue. A, Light micrographs showing conidia (C) of Colletotrichum higginsianum wild-type strain and penetration mutant path-14 germinating on cellophane dialysis membrane after $36 \mathrm{~h}$. The wild-type appressorium penetrated the cellophane to form a hypha inside the membrane $(\mathrm{H})$. Mutant path-14 formed melanized appressoria (A) with penetration pores (PP) but failed to penetrate. Other spores had produced long germ tubes (GT) over the surface of the cellophane. B, Light micrographs comparing penetration of ethanol-killed Arabidopsis leaves by the wildtype strain and mutant path-14. Both the wild-type and mutant formed melanized appressoria (A), but whereas the wild-type rapidly penetrated to form thin hyphae inside the dead tissue, path-14 failed to penetrate. Scale bars $=10 \mu \mathrm{m}$. 
host cell death was restricted to the penetrated epidermal cell (Fig. 7A), but in four mutants (path-26, path-30, path-31, path-33), HR extended to one or more adjacent uninfected epidermal and mesophyll cells (Fig. 7B).

The frequency with which callose papillae were deposited at penetration sites was quantified by staining leaf tissue at 3 dai with aniline blue (Fig. 7C). Figure 6B shows representative data for the $C$. higginsianum wild-type strain and three selected mutants. In the wild type, callose was detected beneath only approximately $25 \%$ of appressoria, and when callose was present, most appressoria successfully penetrated and formed primary hyphae (Fig. 6B). However, in the three mutants, host callose deposition was associated with reduced penetration and failure to establish intracellular primary hyphae (Figs. 6B and 7D). Thus, appressoria of path-27 and path-32 induced callose papillae significantly more frequently than the wild type $(P<$ $0.05)$, and their penetration efficiency was significantly less than wild type $(P<0.05)$ (Fig. 6B). Mutant path-23 induced callose deposition with similar frequency to the wild type, but the papillae were abnormally large (Figs. 6B and 7E) and penetration efficiency was significantly less than the wild type.

To evaluate the contribution of plant defense responses to the infection phenotypes of selected fungal mutants, we used available Arabidopsis mutants impaired in different components of penetration resistance, namely, the PEN1 syntaxin (Collins et al. 2003), the PEN2 $\beta$-glycosyl hydrolase (Lipka et al. 2005), the PEN3 ABC transporter (Stein et al. 2006), and the PMR4/GSL5 callose synthase (Nishimura. et al. 2003). Penetration by path-27 and path-28 was two- to threefold higher on pen 2-2 and pen3-3 mutants than on wild-type Col-0 plants but was not enhanced on penl-1 and pmr4-1 mutants (Fig. 8). These findings suggest that toxic secondary metabolites synthesized by PEN 2 and exported by PEN3 may impede penetration by path-27 and path-28, but callose deposition and PEN1mediated secretion events do not compromise penetration by these mutants. The penetration frequency of wild-type $C$. higginsianum was also greater on pen2-2 and pen3-3 plants, but these differences were not statistically significant.

Mutants impaired in the switch to necrotrophy. A final group of five mutants (path-36 to path-40) were impaired in their ability to make the transition from biotrophy to necrotrophy. The penetration efficiency of these mutants was similar to wild-type $C$. higginsianum (Table 1 ), and the timing and morphology of their development in planta was also indistinguishable from the wild type until the formation of biotrophic primary hyphae. Thereafter, they rarely formed secondary hyphae or entered the destructive necrotrophic phase (Fig. 9A). Thus, even at 7 dai, fungal development was typically restricted to primary hyphae occupying single epidermal cells (Fig. 9A and B). Host cells containing the primary hyphae of such mutants remained alive at least until 7 dai, as demonstrated by their continued ability to plasmolyze, suggesting that these mutants successfully establish and maintain a biotrophic relationship with host cells (Fig. 9B). None of the mutants induced visible host defense responses such as HR or callose deposition with greater frequency than the wild type (data not shown).

\section{Analysis of T-DNA flanking sequences.}

C. higginsianum genomic sequence flanking the T-DNA right border $(\mathrm{RB})$ was recovered from 12 pathogenicity mutants using thermal asymmetric interlaced-polymerase chain reaction (TAIL-PCR) and inverse PCR. The RB sequences obtained by TAIL-PCR were generally shorter $($ mean $=955 \mathrm{bp}$, range 0.3 to $1.2 \mathrm{~kb}$ ) than those from inverse PCR (mean $=1,994 \mathrm{bp}$, range 0.4 to $4.5 \mathrm{~kb}$ ). Inverse PCR was also found to be a more reliable method for mutants with tandem insertions because the restriction digest removed the adjacent T-DNA insert. Open reading frames (ORF) were predicted using FGENESH after obtaining further sequence from a $C$. higginsianum genomic library. Among the 14 T-DNA insertions analyzed in these mutants, nine were located inside a predicted ORF while four were positioned upstream and one downstream of a predicted ORF (Table 2). Seven ORF showed high homology ( $\mathrm{E} \leq 1 \mathrm{e}-$ $65)$ to known fungal proteins with annotated functions (Table 2): a major facilitator superfamily (MFS) transporter, an ATPbinding endoribonuclease, $\beta$-1,3(4)-glucanase, ornithine decarboxylase, importin $\beta 2$ (identified as the tagged gene in two independent mutants), and two genes involved in arginine biosynthesis, namely, carbamoyl-phosphate synthetase and the Arg-6 precursor, which encodes $N$-acetylglutamate kinase and $N$-acetylglutamyl-phosphate reductase. Three tagged genes had significant similarity ( $E \leq 1 \mathrm{e}-20)$ to fungal hypothetical proteins of unknown function, while a further three T-DNA
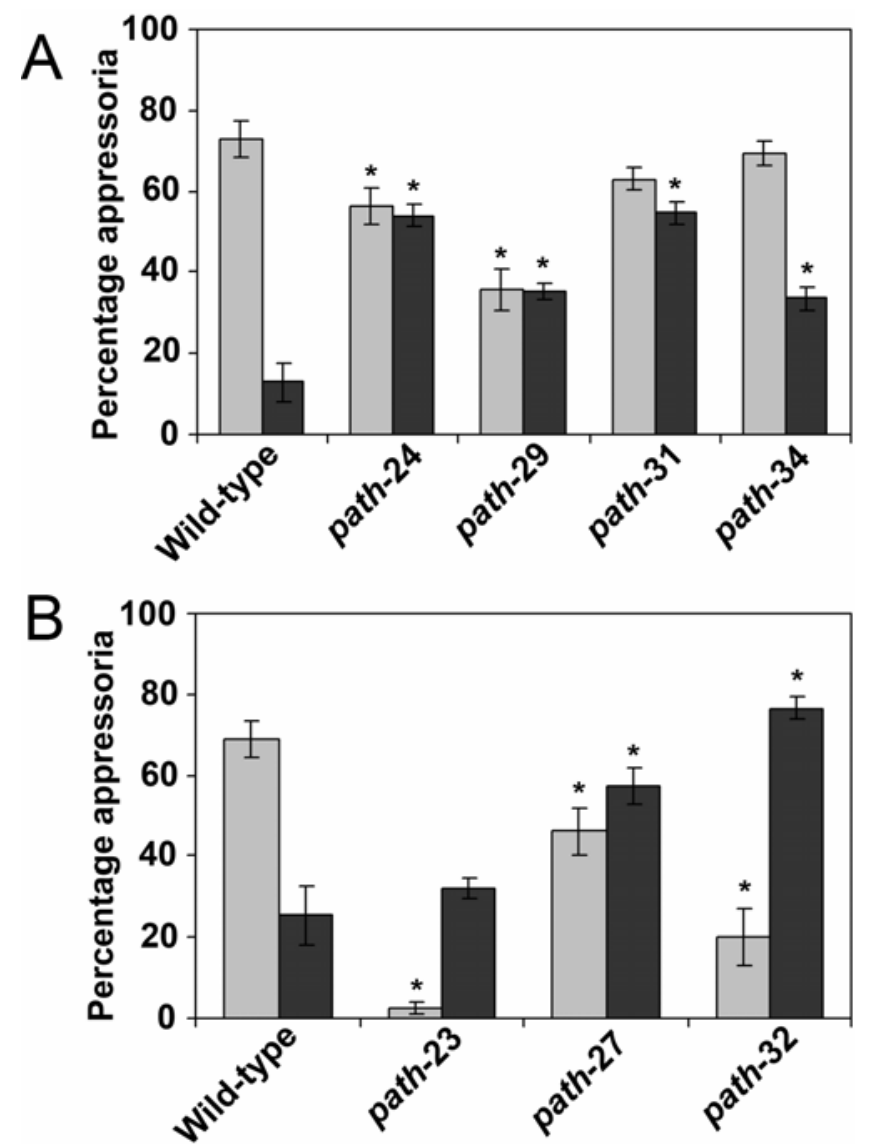

Fig. 6. Quantification of appressorial penetration ability and induction of host defense responses by selected mutants. Arabidopsis plants were spray-inoculated with Colletotrichum higginsianum conidial suspension, and penetration and host defense responses were quantified by microscopy at 3 days after inoculation (dai). Penetration was scored according to whether hyphae were visible in epidermal cells underlying appressoria. Accumulation of $\mathrm{H}_{2} \mathrm{O}_{2}$ and deposition of callose papillae were detected by staining with diaminobenzidine or aniline blue, respectively. At least 100 appressoria were scored for the wild type and mutants, and values represent mean percentages (error bars $=1$ standard error) calculated from three independent experiments. Asterisks indicate values significantly different than the wild type (Student's $t$-test, $P<0.05$ ). A, Graph showing percentage of appressoria penetrating epidermal cells (gray bars) and inducing $\mathrm{H}_{2} \mathrm{O}_{2}$ accumulation in host cells (black bars). Mutants path-24, path-29, path-31, and path-34 all induced $\mathrm{H}_{2} \mathrm{O}_{2}$ accumulation significantly more frequently than did the wild type. $\mathbf{B}$, Graph showing percentage of appressoria penetrating epidermal cells (gray bars) and inducing papillary callose (black bars). Mutants path-27 and path-32 induced significantly more papillae than the wild type, and their penetration efficiency was also significantly reduced. 

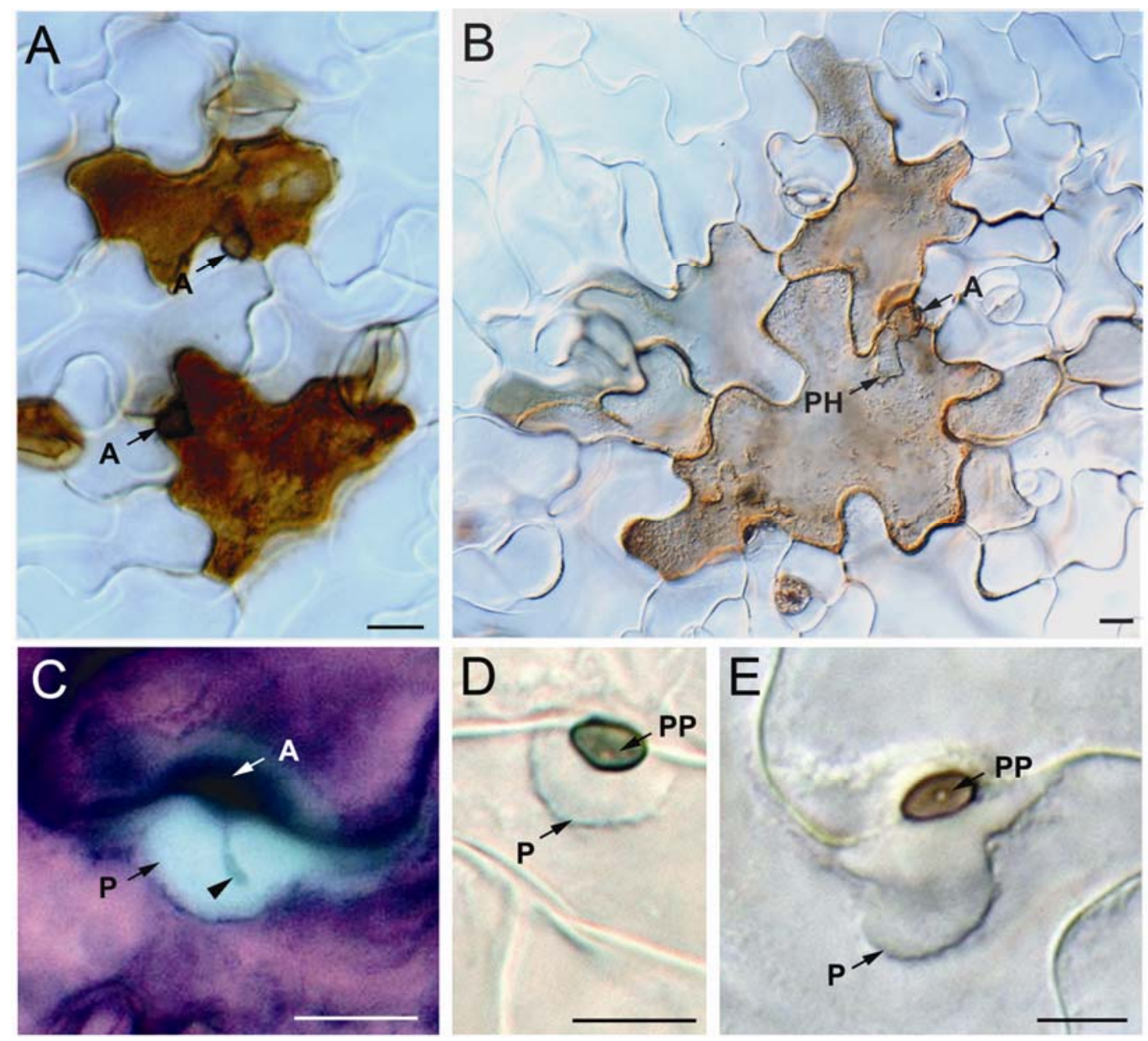

Fig. 7. Accumulation of $\mathrm{H}_{2} \mathrm{O}_{2}$ and papillary callose at attempted penetration sites of Colletotrichum higginsianum pathogenicity mutants. Light micrographs showing host defense responses to selected pathogenicity mutants. Arabidopsis plants were spray-inoculated and were processed for microscopy at 3 days after inoculation (dai). A, and $\mathbf{B}$, Accumulation of $\mathrm{H}_{2} \mathrm{O}_{2}$ in host epidermal cells visualized with 3,3-diaminobenzidine. A, Hydrogen peroxide accumulation was observed in single epidermal cells beneath appressoria of mutant path-29. B, Mutant path-31 induced $\mathrm{H}_{2} \mathrm{O}_{2}$ accumulation not only in the penetrated epidermal cell but also in adjacent uninfected cells. C, Papilla (P) formed beneath an appressorium (A) of mutant path-35 showing aniline blue-induced fluorescence of callose. The fungal penetration peg (arrowhead) is visible within the papilla. D, and E, Papillae beneath appressoria of mutant path-27 (D) and path-23 (E) visualized by differential interference contrast microscopy. $\mathrm{PH}=$ primary hypha and $\mathrm{PP}=$ penetration pore. Scale bars $=10 \mu \mathrm{m}$.

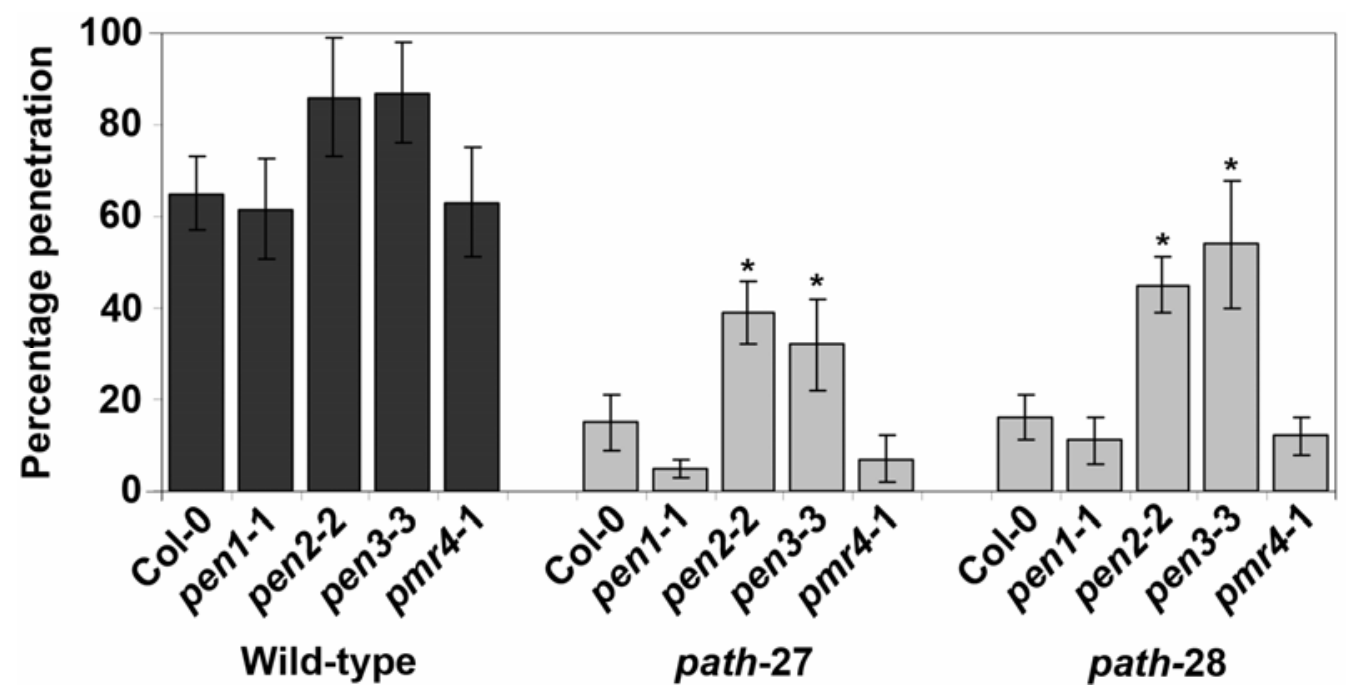

Fig. 8. Contribution of plant defense responses to impaired penetration efficiency of Colletotrichum higginsianum mutants. Arabidopsis mutants impaired in components of penetration resistance (pen1-1, pen2-3, pen3-1, and pmr4-1) and Col-0 wild-type plants were spray-inoculated with conidial suspension of wild-type $C$. higginsianum and mutants path-27 and path-28. After 3 days, penetration was quantified by microscopy according to whether hyphae were visible in epidermal cells underlying appressoria. At least 100 appressoria were scored, and values represent mean percent penetration (error bars $=1$ standard error) calculated from three independent experiments. Penetration by path-27 and path-28 was significantly higher on pen2-3 and pen3-1 mutants than on Col-0 wild-type plants (Student's $t$-test, $P<0.05$ ) but not on pen $1-1$ and pmr $4-1$ mutants. 
insertions were located in predicted ORF without a significant BLAST match $(\mathrm{E} \leq 1 \mathrm{e}-5)$ to any entries in the National Center for Biotechnology Information (NCBI) nonredundant (nr) protein database or the Consortium for the Functional Genomics of Microbial Eukaryotes (COGEME) fungal expressed sequence

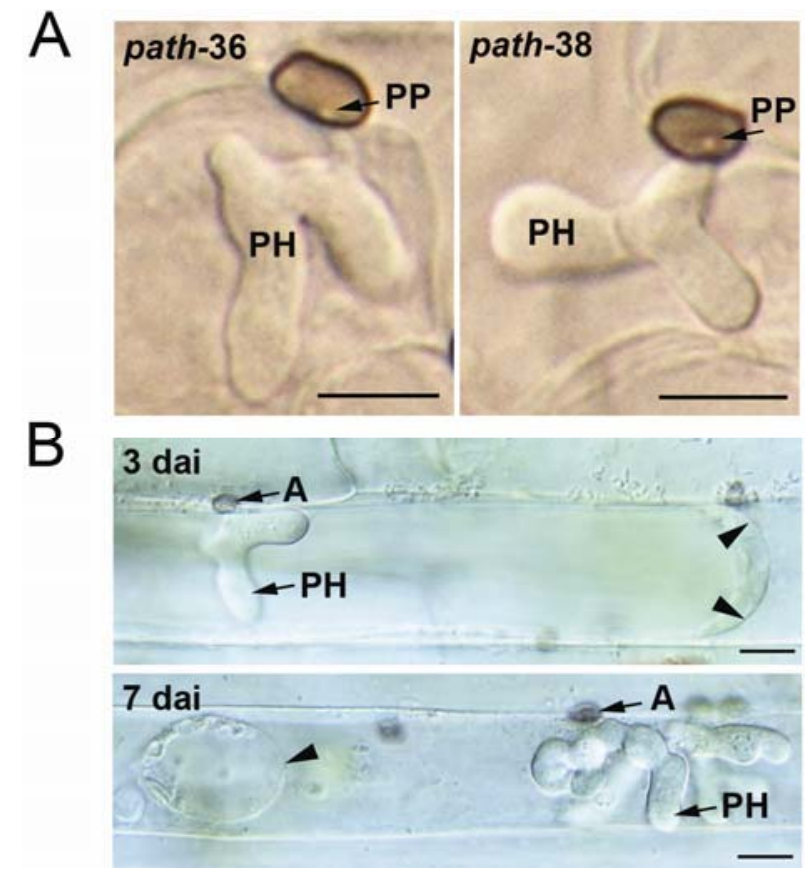

Fig. 9. Colletotrichum higginsianum mutants impaired in the switch from biotrophy to necrotrophy. A, Arabidopsis plants were spray-inoculated with mutants path-36 and path-38, and tissue was cleared for microscopy at 7 days after inoculation (dai). Both mutants formed normal melanized appressoria with penetration pores (PP) and successfully established biotrophic primary hyphae $(\mathrm{PH})$ in host epidermal cells, but necrotrophic secondary hyphae were rarely produced. Scale bars $=10 \mu \mathrm{m}$. B. Plasmolysis test for viability of penetrated epidermal cells. Arabidopsis seedlings were inoculated with mutant path-36 and hypocotyls were plasmolyzed with $0.85 \mathrm{M} \mathrm{KNO}_{3}$. At 3 dai, biotrophic primary hyphae (PH) were visible beneath appressoria (A) and the penetrated epidermal cell remained alive, as shown by its ability to plasmolyze normally (arrowheads indicate the plasma membrane). At 7 dai, the primary hyphae were larger but secondary hyphae were not present and the penetrated host cells were still alive. Scale bars $=10 \mu \mathrm{m}$. tag (EST) database (Table 2). However, all three of these ORF (in path-5, path-8, and path-23) gave significant BLAST matches $(\mathrm{E} \leq 8 \mathrm{e}-12)$ and showed $>78 \%$ sequence identity to trace files from the $C$. graminicola genome sequencing project. No functional motifs or conserved domains were identified using InterProScan or RPS-BLAST in protein translations of those ORF without homology or resembling hypothetical proteins, with the exception of a tagged ORF in path-7 (homologous to Gibberella zeae hypothetical protein FG06146.1), which was predicted to contain multiple WD40 repeats. Using SignalP to identify putative N-terminal signal peptides, the only tagged gene predicted to encode a secreted protein was $\beta$ 1,3(4)-glucanase. This is likely to be a soluble extracellular protein, because it was not predicted to contain either transmembrane domains (TMHMM algorithm) or a C-terminal glycosylphosphatidylinositol (GPI) anchor that would link it to the fungal plasma membrane or cell wall (Fungal Big-PI Predictor).

\section{DISCUSSION}

In this study, we have developed a high-throughput forward genetic screen, based on ATMT-mediated insertional mutagenesis, with the aim of identifying pathogenicity genes in $C$. higginsianum. A total of 40 mutants displaying a range of defects in their pre- and postpenetration development were obtained, and from these, we recovered ORF for 14 T-DNA-tagged loci. These represent putative pathogenicity genes, and further analysis of these should give new insights into molecular interactions between $C$. higginsianum and Arabidopsis.

Using an ATMT protocol based on the cocultivation of Agrobacterium tumefaciens with germinating conidia of $C$. higginsianum, we obtained approximately 100 transformants per $10^{6}$ spores. Although higher transformation efficiencies (up to 17,000 per $10^{6}$ spores) have been reported for some other Colletotrichum species (Maruthachalam et al. 2008; Talhinhas et al. 2008), this was adequate to quickly generate many thousands of transformants for pathogenicity screening. In fungi lacking a sexual stage, such as $C$. higginsianum, multiple TDNA insertions cannot be separated through genetic segregation. To facilitate the recovery of tagged genes from such fungi therefore, it is desirable that the majority of transformants should contain insertions at a single site in the genome (Michielse et al. 2005). Southern blot analysis suggested that $58 \%$ of $C$. higginsianum transformants contained single-copy

Table 2. Summary of Colletotrichum higginsianum genes identified from T-DNA flanking sequences

\begin{tabular}{|c|c|c|c|c|c|c|}
\hline \multirow[b]{2}{*}{ Mutant } & \multirow[b]{2}{*}{ EMBL ID } & \multirow[b]{2}{*}{ Insertions $^{\mathbf{a}}$} & \multirow[b]{2}{*}{ T-DNA insertion ${ }^{b}$} & \multicolumn{3}{|c|}{ Best BLAST match with functional annotation } \\
\hline & & & & Putative function (NCBI accession no.) & Organism & E-value \\
\hline path-5 & FM201309 & 1 & In predicted $\mathrm{ORF}^{\mathrm{c}}$ & Unknown & $\ldots$ & \\
\hline \multirow[t]{2}{*}{ path-7 } & FM201311 & 2 & In ORF & Hypothetical protein (FG06146.1) & Gibberella zeae & $1 \mathrm{e}-116$ \\
\hline & FM201310 & & $1.5 \mathrm{~kb}$ upstream & Hypothetical protein (FG06145.1) & Gibberella zeae & $2 \mathrm{e}-22$ \\
\hline path-8 & FM201314 & 1 & In predicted $O R F^{d}$ & Unknown & $\ldots$ & $\ldots$ \\
\hline path-9 & FM201308 & 1 & $1 \mathrm{~kb}$ downstream & Endo-1,3(4)- $\beta$-glucanase (AFUA_1G05290) & Aspergillus fumigatus & $4 e-68$ \\
\hline path-12 & FM201302 & 1 & In ORF & MFS transporter (NFIA_086030) & Neosartorya fisheri & $8 \mathrm{e}-170$ \\
\hline path-16 & FM201307 & 1 & In ORF & Ornithine decarboxylase (AY602214) & Glomerella lindemuthiana & 0.0 \\
\hline path-19 & FM201305 & 1 & In ORF & Arg-6 protein (EAA35492.1) & Neurospora crassa & 0.0 \\
\hline \multirow[t]{2}{*}{ path-23 } & FM201312 & 2 & $620 \mathrm{bp}$ upstream & Hypothetical protein (FG02446.1) & Gibberella zeae & $2 \mathrm{e}-102$ \\
\hline & FM201313 & & In predicted $\mathrm{ORF}^{\mathrm{c}}$ & Unknown & $\ldots$ & \\
\hline path-29 & FM201304 & 1 & 730 bp upstream & ATP-binding endoribonuclease (ACLA_048430) & Aspergillus clavatus & $5 e-110$ \\
\hline path-35 & FM201306 & $1^{\mathrm{e}}$ & In ORF & Carbamoyl-phosphate synthetase (EAA36214.1) & Neurospora crassa & 0.0 \\
\hline path-36 & FM201303 & 1 & $620 \mathrm{bp}$ upstream & Importin $\beta 2$ subunit (AFUA_1G15900) & Aspergillus fumigatus & 0.0 \\
\hline path-38 & FM201303 & 1 & In ORF & Importin $\beta 2$ subunit (AFUA_1G15900) & Aspergillus fumigatus & 0.0 \\
\hline
\end{tabular}

${ }^{a}$ Number of insertion sites determined by Southern blot hybridization following XhoI digestion of genomic DNA. An XhoI site is present in the T-DNA but outside the $h p h$ probe.

${ }^{\mathrm{b}}$ Putative position relative to open reading frame (ORF). Distance upstream of predicted start codon or downstream of predicted stop codon.

${ }^{\mathrm{c}}$ Open reading frame (ORF) predicted by FGENESH using Fusarium graminearum and Magnaporthe oryzae matrices.

d ORF predicted by FGENESH using Arabidopsis thaliana matrix.

e Polymerase chain reaction (PCR) and Southern blot data were consistent with a multiple insertion event comprising three T-DNA copies at a single site. 
T-DNA insertions, which is greater than the frequency reported for $C$. graminicola $(16 \%)$ but less than obtained with other Colletotrichum species (62 to 86\%) (Maruthachalamet al. 2008; Talhinhas et al. 2008). However, among those $C$. higginsianum transformants harboring multiple T-DNA copies, we found that the majority $(73 \%)$ were integrated at a single site, mostly as tandem repeats in head-to-tail orientation, which did not prevent the amplification of RB flanking sequences by TAIL-PCR or Inverse PCR and identification of the tagged genes.

We detected no integration of plasmid DNA from outside the T-DNA, in contrast to C. graminicola, in which $70 \%$ of ATMT transformants contained tandem integrations of the entire Ti-plasmid (Flowers and Vaillancourt 2005), and C. lagenarium, in which binary vector backbone DNA was detected in $43 \%$ of flanking sequences (Tsuji et al. 2003). Systematic analysis of T-DNA integration events in $M$. grisea showed that insertion is often associated with small target site deletions, and occasionally induces larger deletions of host DNA or chromosomal rearrangements (Choi et al. 2007; Li et al. 2007; Meng et al. 2007). We cannot evaluate the extent to which such events may have occurred during ATMT in $C$. higginsianum, because we did not attempt to obtain both left border and RB flanking sequences. Consistent with studies on other fungi (Choi et al. 2007; Mullins et al. 2001; Tsuji et al. 2003), we found no evidence for truncation of the T-DNA RB, but left border integrity was not determined.

Several recent studies provide evidence that T-DNA integration into fungal genomes is not entirely random. For example, large-scale analyses of randomly selected transformants in $M$. grisea revealed a significant bias for promoter regions, while insertion into coding regions occurred less often than expected (Choi et al. 2007; Li et al. 2007; Meng et al. 2007). Preferential insertion of T-DNA into promoter regions was also detected in Cryptococcus neoformans melanization mutants (Walton et al. 2005). Our analysis of integration events in $C$. higginsianum was based on mutants showing altered pathogenicity phenotypes and, as expected, most T-DNA insertions were located in regions likely to affect gene function. However, we found that insertion into gene coding regions was more frequent (nine) than insertion into putative upstream regulatory regions (four).

Our findings also suggest that there might be 'hot spots' for T-DNA integration within the $C$. higginsianum genome. Thus, out of only 12 pathogenicity mutants for which flanking sequence was obtained, the same gene (an importin- $\beta 2$ homolog) was tagged in two different mutants (path-36 and path-38). Similarly, there is evidence that some rice genes are T-DNAtagged more frequently than would be expected by random insertion (Zhang et al. 2007). We also found that two independent insertions were located only $4 \mathrm{~kb}$ apart in mutant path-7, while in path-23, two tagged genes were identified within the same cosmid clone and must, therefore, be approximately $30 \mathrm{~kb}$ apart, i.e., the average insert size of the cosmid genomic library. Regions of preferential integration could result from differences in chromatin organization, which probably affect accessibility of the host DNA to incoming T-DNAs (Meng et al. 2007). Large-scale studies on M. grisea, Arabidopsis, and rice have also shown a strong correlation between T-DNA insertion sites and expressed genes, suggesting a bias towards transcriptionally active regions of the genome (Barakat et al. 2000; Li et al. 2007; Zhang et al. 2007). Further work is required to determine the extent of nonrandom T-DNA insertion in C. higginsianum, which could make it more difficult to saturate the genome with mutations.

An important aspect of random insertional mutagenesis is the ability to isolate tagged genes from the mutants. We successfully recovered $\mathrm{RB}$ flanking sequences from 12 of 40 pathogenicity mutants (30\%), using TAIL-PCR and inverse
PCR. Our relatively low success rate was similar to that reported for Leptosphaeria maculans (34\%) but less than that obtained with M. grisea (46\%) and Fusarium oxysporum (90\%) (Blaise et al. 2007; Meng et al. 2007; Mullins et al. 2001). In the present study, amplification of RB flanking sequences may have failed due to truncation of the T-DNA RB before the primer annealing site, insertion of inverted (RB to $\mathrm{RB}$ ) tandem repeats or, in the case of inverse PCR, absence of a restriction site close enough to the T-DNA insertion. It may, therefore, be possible to recover flanking regions from some of these recalcitrant mutants using more internal RB primers, left border primers, or different restriction enzymes.

Another concern with the use of ATMT for insertional mutagenesis is the occurrence of untagged mutations. Thus, in Arabidopsis, T-DNA insertion was linked to a mutant phenotype in only 35 to $40 \%$ of ATMT mutants (Azpiroz-Leehan and Feldmann 1997), while in both Leptosphaeria maculans and Cryptococcus neoformans, $50 \%$ of the mutations were TDNA-tagged (Walton et al. 2005). Since it is not possible to analyze cosegregation of the T-DNA and mutant phenotype in C. higginsianum, it is necessary to validate T-DNA tagging by complementation with a wild-type gene copy or by targeted gene disruption. Although the proportion of untagged mutations in our library has yet to be determined, complementation with the corresponding cosmid genomic DNA clones restored full pathogenicity to three mutants, namely, path-12, path-19, and path-35 (unpublished data).

To efficiently prescreen large numbers of ATMT transformants with minimal handling of fungal cultures, we devised a miniaturized pathogenicity assay. By growing both the transformants and Arabidopsis seedlings in a 96-well format, subculturing and plant inoculation could be performed using a multichannel pipettor to transfer spore suspension. In this way, several hundred transformants could be screened in a single experiment. The selection of some false positives in the primary screen probably resulted from plants receiving insufficient inoculum. However, these were efficiently eliminated by two rounds of selection in the secondary screen, in which adult plants were spray-inoculated with a standardized spore concentration. An advantage of this stringent secondary screen was that all the selected mutants had robust, reproducible phenotypes, but those with minor reductions in pathogenicity were probably missed.

After screening 8,850 primary transformants, we obtained 40 mutants $(0.45 \%)$ that were either nonpathogenic or strongly reduced in their pathogenicity on both Arabidopsis and Brassica plants. A similar proportion of pathogenicity mutants were identified after insertional mutagenesis of other Colletotrichum species and $M$. grisea using ATMT or REMI, although higher frequencies have been obtained with some other pathogens (Table 3). Microscopic analysis of infected tissues allowed us to classify the mutants according to the stage at which fungal development was arrested and the extent to which host defense responses were induced. Overall, we obtained nearly equal numbers of mutants affected in their prepenetration development on the plant surface and postpenetration development inside host cells. None of the 40 pathogenicity mutants were impaired in conidiation or germination, probably because the use of spore suspension for subculturing and infection assays would have eliminated such mutants from the screen. Moreover, apart from melanization defects, none of the mutants showed significant morphological abnormalities in their spores or infection structures formed in planta.

In both Colletotrichum and Magnaporthe spp., a large number of genes involved in the induction and morphogenesis of appressoria have been identified using forward and reverse genetic approaches (Deising et al. 2000). Surprisingly, none of 
the pathogenicity mutants obtained in the present study were affected in their ability to form appressoria on leaf surfaces. However, we identified a relatively large number of appressorium melanization mutants (6 of 8,850 transformants), based on their complete loss of pathogenicity on Arabidopsis. This proportion is comparable to targeted screens for melanin mutants in C. lagenarium (8 of 5,000) and Cryptococcus neoformans (19 of 12,000), based on the loss of colony pigmentation (Tsuji et al. 2003; Walton et al. 2005). All the C. higginsianum melanin mutants produced albino or weakly melanized appressoria that were incapable of penetrating intact host epidermis or cellophane, as expected given the crucial role of melanin in generating turgor pressure for penetration (Deising et al. 2000). In the albino mutant path-5, T-DNA was inserted into a predicted ORF with no homology to any known proteins and without any recognizable functional domains but that matched to trace files from the $C$. graminicola genome sequence. This may therefore be a novel Colletotrichum-specific gene that is required for melanin biosynthesis or its regulation. However, linkage of this ORF with the mutant phenotype requires verification, since path-5 harbored a second T-DNA insertion for which no flanking sequence was obtained.

A total of 15 of the pathogenicity mutants elaborated melanized appressoria with normal morphology but were unable to penetrate living host cells and, in some cases, also inert surfaces, i.e., cellophane and dead leaf tissue. In one such mutant, path-9, the tagged gene resembled fungal mixed-linked endoglucanases, a class of secreted enzymes that degrade $\beta-1,3-, \beta$ $1,4-$, and $\beta-1,3-\beta-1,4$-glucans (Kim et al. 2001). It is conceivable that such an enzyme could function in penetration of the plant cell wall or callose papillae or function in remodeling fungal cell-wall glucans during penetration peg formation. However, in Cochliobolus carbonarum, the mutation of two such enzymes, MLG1 and $M L G 2$, did not affect virulence on maize (Kim et al. 2001).

In path-16, the tagged gene was highly homologous to ornithine decarboxylase (ODC), which catalyzes the first step of the polyamine biosynthesis pathway, although path-16 was not an auxotroph. Polyamines are known to be important for fungal differentiation, e.g., ODC is required for spore germination and sporulation in members of order Mucorales (MartinezPacheco et al. 1989) and the dimorphic transition in Ustilago maydis (Guevara-Olvera et al. 1997). ODC also contributes to virulence in the wheat pathogen Stagonospora nodorum (Bailey et al. 2000). Although polyamine biosynthesis was not previously implicated in appressorial penetration, it may be required for differentiation of the penetration peg and the transition to invasive growth.

The tagged genes in two further mutants were highly homologous to genes involved in arginine biosynthesis, namely, arginine-specific carbamoyl-phosphate synthetase (in path-35) and the Neurospora crassa Arg-6 gene (in path-19) encoding a polyprotein precursor that is processed in the mitochondrial matrix to give $\mathrm{N}$-acetylglutamate kinase and $\mathrm{N}$-acetylglutamylphosphate reductase (Caldovic and Tuchman 2003). As expected, both mutants were arginine auxotrophs. The depletion of stored arginine during spore germination and appressorium formation could explain their reduced ability to penetrate leaf epidermis and cellophane. However, appressoria of both mutants induced significantly more host papillae than the wild type, which may have further impeded their penetration of living epidermal cells. In Fusarium oxysporum, mutation of $\arg 1$, encoding argininosuccinate lyase, showed that arginine biosynthesis was also required for pathogenicity on melon (Namiki et al. 2001). It is remarkable that out of only 12 characterized pathogenicity mutants, two were affected in the same biochemical pathway, suggesting that the ability to synthesize arginine is critical for early stages of host infection by $C$. hig ginsianum.

In path-12, the tagged gene was highly homologous to conserved MFS transporters of other fungi and, in particular, plasma membrane $\mathrm{H}^{+}$symporters involved in the uptake of inorganic phosphate. The infection phenotype of path-12 suggests that phosphate availability could be a limiting factor for $C$. higginsianum during penetration and early growth in planta. Consistent with this finding, the expression of two secreted enzymes with possible roles in phosphate acquisition, namely, homologs of phytase A and acid phosphatase PHO1, was strongly upregulated during early stages of maize infection by $C$. graminicola (Tang et al. 2006).

Fourteen mutants induced cytologically detectable defense responses (i.e., HR or papillae) upon penetration of host epidermal cells. Such mutants may be affected in genes required for evading host recognition or suppressing host cell death or defense responses during the intracellular biotrophic phase. Examples from other Colletotrichum species include $\mathrm{Cg} D \mathrm{~N} 3$, encoding a secreted protein required in $C$. gloeosporioides to suppress HR (Stephenson et al. 2000), and ClaSSD1, a regulator of cell-wall assembly in $C$. lagenarium required to avoid papilla induction (Tanaka et al. 2007). To experimentally test the involvement of host responses in the phenotypes of these fungal mutants, we took advantage of available Arabidopsis mutants affected in components of penetration resistance. Evidence was obtained that the PEN2 $\beta$-glycosyl hydrolase and PEN3 ABC transporter contribute to preventing establishment of biotrophic hyphae by path-27 and path-28. PEN2 and PEN3 both operate in the same defense pathway and function to synthesize toxic secondary metabolites and export them across the plasma membrane, respectively (Stein et al. 2006). The fungal mutants may, therefore, be more sensitive to these toxins or unable to suppress this host defense pathway.

In the HR-inducing mutant path-29, the T-DNA was inserted upstream of an ORF that is homologous to ATP-binding L-PSP (liver perchloric acid-soluble protein) mRNA endoribonucleases and contains YjgH and YjgF conserved domains. This poorly characterized protein family occurs in prokaryotes, archaea, and

Table 3. Comparison of forward genetic screens for fungal pathogenicity mutants

\begin{tabular}{|c|c|c|c|}
\hline Pathogen and source & Method $^{\mathbf{a}}$ & No. ${ }^{b}$ & Mutants (\%) \\
\hline \multicolumn{4}{|c|}{ Colletotrichum higginsianum } \\
\hline This study & ATMT & 8,850 & 0.45 \\
\hline \multicolumn{4}{|l|}{ Colletotrichum acutatum } \\
\hline Talhinhas et al. 2008 & ATMT & 1,500 & 0.33 \\
\hline \multicolumn{4}{|c|}{ Colletotrichum lindemuthianum } \\
\hline Dufresne et al. 1998 & REMI & 600 & 0.67 \\
\hline \multicolumn{4}{|c|}{ Colletotrichum graminicola } \\
\hline Thon et al. 2000 & REMI & 660 & 0.30 \\
\hline \multicolumn{4}{|l|}{ Magnaporthe grisea } \\
\hline Betts et al. 2007 & ATMT & 33,943 & 0.38 \\
\hline \multicolumn{4}{|l|}{ Magnaporthe grisea } \\
\hline Balhadére et al. 1999 & REMI & 3,527 & 0.43 \\
\hline \multicolumn{4}{|l|}{ Magnaporthe grisea } \\
\hline Sweigard et al. 1998 & REMI & 5,538 & 0.49 \\
\hline \multicolumn{4}{|l|}{ Magnaporthe oryzae } \\
\hline Jeon et al. 2007 & ATMT & 21,070 & 0.96 \\
\hline \multicolumn{4}{|l|}{ Ustilago maydis } \\
\hline Bolker et al. 1995 & REMI & 1,000 & 1 to 2 \\
\hline \multicolumn{4}{|l|}{ Fusarium graminaerum } \\
\hline Seong et al. 2005 & REMI & 6,500 & 0.17 \\
\hline \multicolumn{4}{|l|}{ Leptosphaeria maculans } \\
\hline Blaise et al. 2007 & ATMT & 1,388 & 3.9 \\
\hline
\end{tabular}


eukaryotes and has been implicated in diverse cellular processes, including inhibition of protein synthesis and the biosynthesis of purines and isoleucine (Christopherson et al. 2008; Morishita et al. 1999). The top BLAST match was to a putative L-PSP endoribonuclease from $M$. grisea (MGG_00500), which was mutated in a large-scale ATMT insertional mutagenesis program (Jeon et al. 2007). Interestingly, the $M$. grisea mutant also showed reduced pathogenicity on rice but, unlike the $C$. higginsianum mutant, it was impaired in appressorium formation.

We identified five mutants that successfully established intracellular biotrophy but then became arrested at the primary hypha stage and only rarely entered the necrotrophic phase or formed secondary hyphae. Although fundamental to the infection process of all hemibiotrophic Colletotrichum species, the regulation of this major lifestyle transition is poorly understood. To date, only three genes were implicated in the switch from biotrophy to necrotrophy: CLNRI and CLTAl from C. lindemuthianum, which encode an AreaA-like regulator of nitrogen metabolism and a GAL4-like transcriptional activator, respectively, and $C P R l$ from $C$. graminicola, which encodes a subunit of the signal peptidase complex (Dufresne et al. 2000; Pellier et al. 2003; Thon et al. 2002). In two of the $C$. higginsianum mutants affected in this transition, the tagged gene showed high homology to conserved importin- $\beta 2$ proteins, including human karyopherin- $\beta 2$ and yeast Kap104p. This class of importins has not been studied in filamentous fungi, but in mammals, yeast, and plants, they are known to mediate the nuclear import of pre-mRNA processing proteins (Guisbert et al. 2007; Lee et al. 2006). Misregulation of pre-mRNA processing through the loss of such an importin could thus profoundly affect fungal gene expression and pathogenicity.

In conclusion, insertional mutagenesis by ATMT has allowed us to identify 14 genes with potential roles in appressorial pigmentation, host penetration, avoidance or suppression of host defenses, nutrition in planta, and the switch from biotrophy to necrotrophy. None of these genes were previously implicated in the pathogenicity of any Colletotrichum species, and only ODC and the L-PSP endoribonuclease were reported as pathogenicity genes in other fungi. Verification of these candidates by complementation and targeted gene disruption is ongoing, and their detailed functional characterization will be the subject of future reports. Overall, despite revealing some evidence for nonrandom T-DNA integration, our study demonstrates that insertional mutagenesis by ATMT has great potential for the large-scale discovery of novel pathogenicity genes and future genome annotation in C. higginsianum.

\section{MATERIALS AND METHODS}

\section{Bacterial and fungal strains.}

The Agrobacterium tumefaciens C58C1 was used as T-DNA donor for fungal transformation. The bacteria harbored either binary vector $\mathrm{pBIG} 2 \mathrm{RHPH} 2$, which carries the hygromycin $\mathrm{B}$ phosphotransferase $(h p h)$ cassette (Tsuji et al. 2003), or pBINGFP-hph, which carries both the $h p h$ and green fluorescent protein ( $g f p$ ) genes (O'Connell et al. 2004). Agrobacteria were grown at $28^{\circ} \mathrm{C}$ on Luria Bertani (LB) agar supplemented with $50 \mu \mathrm{g}$ of rifampicin and $50 \mu \mathrm{g}$ of kanamycin per milliliter. The fungal recipient, Colletotrichum higginsianum IMI349061, was originally isolated from Brassica campestris (O'Connell et al. 2004). Cultures were maintained on Mathur's agar medium at $25^{\circ} \mathrm{C}$, and conidia were harvested from 7 - to 10 day-old cultures (O'Connell et al. 2004).

\section{Plant material.}

The susceptible host plants used for inoculation experiments were Arabidopsis thaliana ecotypes Landsberg erecta (Ler-0) and wild rape kale, Brassica napus biennis (Horticulture Research International Genetic Resource Unit, accession number 5671). The Arabidopsis mutants penl-1 (Collins et al. 2003), pen2-2 (Lipka et al. 2005), pen3-3 (Stein et al. 2006), and pmr4-1 (Nishimura et al. 2003) were all in the Columbia (Col0 ) background. Plants were grown in soilless compost in a controlled environment chamber (10-h light period, 150 to 200 $\mu \mathrm{mol} \mathrm{m} \mathrm{m}^{-2} \mathrm{~s}^{-1}, 23^{\circ} \mathrm{C}, 65 \%$ relative humidity). Arabidopsis seedlings were grown in sterile compost, using the insert from a micropipette tip box to space the plants in a 96-well format (Supplementary Fig. 3). Mature Arabidopsis plants and Brassica seedlings were grown in 9-cm pots, nine plants per pot.

\section{Fungal transformation.}

The protocol used for ATMT was modified from that of Tsuji and associates (2003) and Takahara and associates (2004). Bacterial cultures were diluted to an optical density at $660 \mathrm{~nm}$ of 0.4 to 0.5 and were mixed $1: 1$ with conidial suspension $\left(10^{6}\right.$ spores $\left./ \mathrm{ml}\right)$ in glycerol induction (GI) broth (Cangelosi et al. 1991) supplemented with $200 \mu \mathrm{M}$ acetosyringone. Aliquots $(200 \mu \mathrm{l})$ were spread over disks of cellophane membrane (MAXI gel-drying cellophane; Carl Roth, Karslruhe, Germany) supported on GI agar supplemented with acetosyringone in 9$\mathrm{cm}$ petri dishes. After cocultivation at 21 to $22^{\circ} \mathrm{C}$ for $48 \mathrm{~h}$, the membranes were removed, inverted, and placed cell-side down onto PDA (Merck, Darmstadt, Germany) containing hygromycin $(100 \mu \mathrm{g} / \mathrm{ml})$, cefotaxime $(50 \mu \mathrm{g} / \mathrm{ml})$, and spectinomycin $(50 \mu \mathrm{g} / \mathrm{ml})$. The membranes were removed after 3 days and, after incubation for a further 3 to 5 days, transformant colonies were transferred to PDA plates containing $100 \mu \mathrm{g}$ of hygromycin per milliliter. Rapidly growing colonies were transferred to 96-well plates (Rotilabo Mikrotest plates, Carl Roth) containing $100 \mu \mathrm{l}$ PDA-hygromycin per well.

\section{Pathogenicity assays.}

In a primary screen for fungal transformants with altered pathogenicity, conidial suspensions (of undefined spore concentration) were prepared from 96-well plate cultures by adding $100 \mu \mathrm{l}$ of sterile deionized water to each well and aspirating several times. Droplets of conidial suspension $(20 \mu \mathrm{l})$ were then inoculated onto 10-day-old Arabidopsis Ler-0 seedlings grown in a 96-well format, using a multichannel pipettor. The inoculated plants were placed in sealed propagator boxes to maintain $100 \%$ humidity and were incubated in a controlled environment chamber (16-h light period, 20 to $60 \mu \mathrm{mol} \mathrm{m} \mathrm{m}^{-2} \mathrm{~s}^{-1}$, $24^{\circ} \mathrm{C}$ ). The seedlings were examined for the presence of disease symptoms 7 dai, using a stereo fluorescence microscope (Leica MZ FLIII; Leica Microsystems, Wetzlar, Germany) equipped with a long-pass filter set for viewing green fluorescence (excitation filter BP450-490, barrier filter LP520). Healthy plant tissues showed red chlorophyll autofluorescence, while dead tissues autofluoresced green. In addition, the mycelia of transformants harboring pBIN-GFP-hph showed green fluorescence. Transformants that extensively colonized host tissue and caused maceration or large necrotic lesions on one or more seedlings were scored as pathogenic. All transformants were screened in this way at least twice, and those that consistently caused no symptoms or only small flecks of green fluorescence were selected as putative pathogenicity mutants and were grown further in 9-cm plates of PDA-hygromycin medium.

In a secondary screen, conidial suspension $\left(5 \times 10^{5}\right.$ spores per milliliter) was prepared from the putative pathogenicity mutants and spray-inoculated onto nine mature Arabidopsis Ler- 0 plants ( 3 to 4 weeks old) using an atomizer. Inoculated plants were incubated under the same conditions as for the primary screen, and after 7 days, symptoms were assessed and tissue samples collected for light microscopy. The altered infec- 
tion phenotype of selected transformants was confirmed by at least one repetition of the pathogenicity assay on both mature Arabidopsis plants and Brassica seedlings (8 days old), using spore suspensions derived from monoconidial cultures. Transformants that, compared with the wild type, consistently showed reduced macroscopic symptoms, reduced fungal colonization, or increased induction of host defense responses (e.g., papilla formation or HR) were considered pathogenicity mutants and were selected for detailed characterization.

\section{Light microscopy.}

To observe the extent of fungal colonization, infected leaf tissues were cleared in ethanol and chloroform (3:1), mounted in lactophenol, and viewed by differential interference contrast microscopy. To detect $\mathrm{H}_{2} \mathrm{O}_{2}$ accumulation in host cells undergoing the hypersensitive response, leaves were stained with $0.1 \%$ (wt/vol) DAB (Thordal-Christensen et al. 1997). To detect callose papillae at fungal penetration sites, tissues were stained with $0.01 \%$ (wt/vol) aniline blue (Fernandez and Heath 1986) and were observed by epifluorescence microscopy (excitation filter G365, dichroic mirror FT395, barrier filter LP420). To test plant cell viability, Arabidopsis seedling hypocotyls were plasmolyzed with $0.85 \mathrm{M} \mathrm{KNO}_{3}$ (O'Connell et al. 2004). All samples were examined with a Zeiss Axioplan 20 microscope (Carl Zeiss, Oberkochen, Germany). For quantifying appressorial penetration efficiency, HR, and callose deposition, at least 100 appressoria were scored on three separate leaves, and experiments were replicated three times. The Student's $t$-test was used to determine the statistical significance of differences between mutants and the wild type, applying the Holm method of $P$-value adjustment to control the false discovery rate resulting from multiple pair-wise comparisons (Holm 1979).

\section{Characterization of fungal growth and development.}

Assays for auxotrophic mutants. The growth rate of putative pathogenicity mutants was measured on different nutrient media and compared with that of the $C$. higginsianum wild-type strain. Four mycelial plugs $(1 \times 1 \mathrm{~mm})$ from the growing edge of a colony were transferred to either rich medium (PDA) or minimal medium (Czapek-Dox agar [CDA]; Merck), and colony diameters were measured after incubation for 4 days at $25^{\circ} \mathrm{C}$. Mutants showing severely reduced growth on both media were not studied further. Mutants showing normal growth on PDA but reduced growth on CDA were tested for auxotrophy in liquid culture as follows. Conidia were resuspended in Czapek-Dox broth $\left(1 \times 10^{3}\right.$ spores per milliliter $)$ and were incubated at $25^{\circ} \mathrm{C}$ for 3 days, with shaking (130 rpm). Mycelium was collected on Merck No. 410 filter paper, dried overnight at $60^{\circ} \mathrm{C}$, and weighed. Mutants showing a reduction in mycelial dry weight of $\geq 69 \%$ compared with the wild type were considered to be auxotrophs.

Appressorial penetration and invasive growth assays. The ability of appressoria to penetrate living host epidermal cells was determined by light microscopy of cleared leaf tissue at 7 dai and by quantification of the percentage of appressoria beneath which intracellular hyphae were visible in underlying epidermal cells. To assess the ability of appressoria to penetrate cellophane, conidial suspension was placed onto pieces of sterile cellophane (Visking dialysis membrane, Carl Roth) supported on $3 \%(\mathrm{wt} / \mathrm{vol})$ water agar and was incubated at $25^{\circ} \mathrm{C}$ and $100 \%$ humidity. The presence of hyphae growing in the cellophane beneath appressoria, indicating successful penetration, was determined by light microscopy after 36 to $48 \mathrm{~h}$. To assess the ability of appressoria to penetrate dead host tissue, Arabidopsis leaves were killed by immersion in ethanol for 3 days and then gradually rehydrated and washed exhaustively with sterile water. The leaves were then placed on sterile mi- croscope slides, inoculated with spore suspension, and incubated at $25^{\circ} \mathrm{C}$ and $100 \%$ humidity. The extent of fungal penetration and colonization of the dead tissue was determined by light microscopy after $18 \mathrm{~h}$. To test invasive growth ability, the rosette leaves of intact Arabidopsis plants were wounded by stabbing with a needle, and droplets of conidial suspension were placed directly onto the wound sites. Symptoms and lesion size were observed after 7 days incubation under the same conditions as used for pathogenicity assays.

\section{Molecular analysis of transformants.}

DNA extraction and Southern hybridization. For extraction of genomic DNA, mycelia were grown in potato dextrose broth for 3 days at $25^{\circ} \mathrm{C}$ with shaking (140 rpm) and were harvested by filtration. DNA was extracted in lysis buffer (100 $\mathrm{mM}$ Tris- $\mathrm{HCl}, \mathrm{pH}$ 8.0, $100 \mathrm{mM}$ EDTA, $50 \mathrm{mM} \mathrm{NaCl}, 10 \mathrm{mM}$ 2-mercaptoethanol, $0.5 \%$ [wt/vol] sodium dodecyl sulfate), and after PronaseE treatment, DNA was purified by phenol extraction and isopropanol precipitation, followed by RNase treatment, phenol extraction, and ethanol precipitation. PCR was used to confirm the presence of T-DNA insertions by amplifying a 578-bp internal region of the $h p h$ gene with primers hphF and hphR (Table 4). For Southern blot hybridization, genomic DNA was digested to completion with $10 \mathrm{U}$ of restriction enzymes XbaI and XhoI (New England Biolabs, Frankfurt, Germany), hybridized with the 578-bp PCR probe synthesized with primers $h p h F$ and $h p h R$, and labeled with digoxigenin (DIG)-dUTP, using the PCR DIG probe synthesis kit (Roche, Mannheim, Germany) according to the manufacturer's instructions. Hybridization was detected using the DIG luminescence detection kit (Roche).

Analysis of T-DNA flanking sequences. Genomic DNA sequences flanking T-DNA insertions were amplified by TAILPCR and inverse PCR using the primer sequences shown in Table 4. For TAIL-PCR, genomic DNA was used as template in successive reactions using nested RB-specific primers HS1, HS2, and HS3 for pBIG2RHPH2 (Tsuji et al. 2003) and TS4, TS5, and TS6 for pBIN-GFP-hph together with the degenerate primers AD1 or AD2 (Liu and Whittier 1995; Mullins et al. 2001). Thermal settings for TAIL-PCR were as described by Tsuji and associates (2003), using Ampliqon Taq DNA polymerase (VWR-Bie \& Berntsen, Copenhagen, Denmark).

For inverse PCR, genomic DNA was digested with suitable restriction enzymes and circularized with T4 DNA ligase (Invitrogen, Karlsruhe, Germany). The ligated product was then extracted with phenol and precipitated with ethanol and dissolved in Tris-EDTA (Ochman et al. 1988). First-round PCR was performed in reactions containing $2 \mu \mathrm{l}$ of the ligation product using LA Taq polymerase and GC buffer I or II, with 24 cycles of denaturation at $94^{\circ} \mathrm{C}$ for $30 \mathrm{~s}$, primer annealing at $55^{\circ} \mathrm{C}$ for $30 \mathrm{~s}$, and extension by LA Taq polymerase (Takara

Table 4. Primer sequences used for polymerase chain reaction

\begin{tabular}{lll}
\hline Primer & \multicolumn{1}{c}{ Sequence } & ${ }^{\circ} \mathbf{C}$ \\
\hline HS1 & GGCCGTGGTTGGCTTGTATGGAGCAGCAGA & 74 \\
HS2 & TGGTCTTGACCAACTCTATCAGAGCTTGGT & 67 \\
HS3 & TCTGGACCGATGGCTGTGTAGAAGTACTCG & 69 \\
TS4 & TACAGATGCATGACGGCCATCATGCCAACG & 71 \\
TS5 & AACTGGCCCTTATCGTACTCCATGTTGGTA & 67 \\
TS6 & AGCAGGCTCGACGTATTTCAGTGTCGAAAG & 68 \\
AD1 & NGTCGASWGANAWGAA & $47^{\mathrm{a}}$ \\
AD2 & GTNCGASWCANAWGTT & $47^{\mathrm{a}}$ \\
hphF & ACTCACCGCACGTCTGTCG & 67 \\
hphR & TGCGGCCATTGTCCGTCAGG & 67 \\
RBsp & TCAGATTGTCGTTTCCCGCC & 61 \\
SP6P & ATTTAGGTGACACTATAG & 46 \\
\hline
\end{tabular}

a Average temperature. 
Bio, Saint-Germain-en-Laye, France) at $72^{\circ} \mathrm{C}$ for $5 \mathrm{~min}$. The second nested PCR was performed with the same PCR program using $1 \mu \mathrm{l}$ of the first-round PCR product (diluted 1:100) as a template together with nested primers.

TAIL-PCR and inverse PCR reactions yielding single products with the expected size shift were sequenced directly using the RB primer RBsp. For TAIL-PCR reactions yielding multiple products, these were first separated on a gel and were cloned into the plasmid pGEM-T Easy (Promega, Mannheim, Germany), prior to transformation into Escherichia coli DH5 $\alpha$ and sequencing with primer SP6P or RBsp. DNA sequences were determined by the Max Plank Institut für Züchtungsforschung DNA core facility on Applied Biosystems Abi Prism 377, 3100, and 3730 sequencers using BigDye-terminator v3.1 chemistry.

To isolate wild-type copies of loci tagged by T-DNA, flanking sequences recovered by TAIL-PCR and inverse PCR were used to screen a cosmid genomic library prepared from $C$. higginsianum IMI 349061. Further sequence was then obtained from the cosmid clones by primer walking using gene-specific primers. Using appropriate BLAST algorithms (Altschul et al. 1997), sequence homology searches were performed against the NCBI nr protein database, fungal EST from the COGEME database (Soanes and Talbot 2006), the Pathogen-Host Interactions database of experimentally verified pathogenicity genes (Baldwin et al. 2006), and raw sequence reads from the Colletotrichum graminicola genome project (NCBI trace archive). The FGENESH program (Softberry Inc., Mount Kisco, NY. U.S.A.) was used for gene structure prediction using the Fusarium graminearum, Magnaporthe oryzae, and Arabidospsis thaliana matrices. Functional motifs were sought by querying predicted protein sequences against the NCBI conserved domain database using RPS BLAST and InterProScan. Potential signal peptides, transmembrane helices, and GPI anchors were sought using SignalP 3.0, TMHMM (transmembrane prediction using hidden Markov models), and the Fungal Big-PI Predictor, respectively (Eisenhaber et al. 2004; Emanuelsson et al. 2007).

\section{ACKNOWLEDGMENTS}

We thank G. Tsuji (Kyoto Prefectural University, Japan) for providing vectors pBIG2RHPH2 for ATMT and pBIG5CosB1 for construction of a cosmid genomic library and D. Astley (Genetic Resources Unit, Warwick HRI, Wellesbourne, U.K.) for providing Brassica seed. This work was funded by the Max-Planck-Gesellschaft (München, Germany). A. Huser was supported by a Marie Curie Fellowship for Early Stage Research Training and H. Takahara was supported by a Max Planck postdoctoral fellowship.

\section{LITERATURE CITED}

Altschul, S. F., Madden, T. L., Schaffer, A. A., Zhang, J., Zhang, Z., Miller, W., and Lipman, D. J. 1997. Gapped BLAST and PSI-BLAST: A new generation of protein database search programs. Nucleic Acids Res. 25:3389-3402.

Azpiroz-Leehan, R., and Feldmann, K. A. 1997. T-DNA insertion mutagenesis in Arabidopsis: Going back and forth. Trends Genet. 13:152156.

Bailey, A., Mueller, E., and Bowyer, P. 2000. Ornithine decarboxylase of Stagonospora (Septoria) nodorum is required for virulence toward wheat. J. Biol. Chem. 275:14242-14247.

Baldwin, T. K., Winnenburg, R., Urban, M., Rawlings, C., Koehler, J., and Hammond-Kosack, K. E. 2006. The Pathogen-Host Interactions database (PHI-base) provides insights into generic and novel themes of pathogenicity. Mol. Plant-Microbe Interact. 19:1451-1462.

Balhadére, P. V., Foster, A. J., and Talbot, N. J. 1999. Identification of pathogenicity mutants of the rice blast fungus Magnaporthe grisea by insertional mutagenesis. Mol. Plant-Microbe Interact. 12:129-142.

Barakat, A., Gallois, P., Raynal, M., Mestre-Ortega, D., Sallaud, C., Guiderdoni, E., Delseny, M., and Bernardi, G. 2000. The distribution of
T-DNA in the genomes of transgenic Arabidopsis and rice. FEBS (Fed. Eur. Biochem. Soc.) Lett. 471:161-164.

Betts, M. F., Tucker, S. L., Galadima, N., Meng, Y., Patel, G., Li, L., Donofrio, N., Floyd, A., Nolin, S., Brown, D., Mandel, M. A., Mitchell, T. K., Xu, J. R., Dean, R. A., Farman, M. L., and Orbach, M. J. 2007. Development of a high throughput transformation system for insertional mutagenesis in Magnaporthe oryzae. Fungal Genet. Biol. 44:10351049.

Blaise, F., Remy, E., Meyer, M., Zhou, L., Narcy, J. P., Roux, J., Balesdent, M. H., and Rouxel, T. 2007. A critical assessment of Agrobacterium tumefaciens-mediated transformation as a tool for pathogenicity gene discovery in the phytopathogenic fungus Leptosphaeria maculans. Fungal Genet. Biol. 44:123-138.

Bolker, M., Bohnert, H. U., Braun, K. H., Gorl, J., and Kahmann, R.1995. Tagging pathogenicity genes in Ustilago maydis by restriction enzymemediated integration (REMI). Mol. Gen. Genet. 248:547-552.

Caldovic, L. and Tuchman, M. 2003. $N$-acetylglutamate and its changing role through evolution Biochem. J. 372:279-290.

Cangelosi, G. A., Best, E. A., Martinetti, G., and Nester, E. W. 1991. Genetic analysis of Agrobacterium. Methods Enzymol. 204:384-397.

Choi, J., Park, J., Jeon, J., Chi, M. H., Goh, J., Yoo, S. Y., Park, J., Jung, K., Kim, H., Park, S. Y., Rho, H. S., Kim, S., Kim, B. R., Han, S. S., Kang, S., and Lee, Y. H. 2007. Genome-wide analysis of T-DNA integration into the chromosomes of Magnaporthe oryzae. Mol. Microbiol. 66:371-382.

Christopherson, M. R., Schmitz, G. E., and Downs, D. M. 2008. YjgF is required for isoleucine biosynthesis when Salmonella enterica is grown on pyruvate medium. J. Bacteriol. 190:3057-3062.

Collins, N. C., Thordal-Christensen, H., Lipka, V., Bau, S., Kombrink, E., Qiu, J. L., Huckelhoven, R., Stein, M., Freialdenhoven, A., Somerville, S. C., and Schulze-Lefert, P. 2003. SNARE-protein-mediated disease resistance at the plant cell wall. Nature 425:973-977.

de Groot, M. J. A., Bundock, P., Hooykaas, P. J. J., and Beijersbergen, A. G. M. 1998. Agrobacterium tumefaciens-mediated transformation of filamentous fungi. Nat. Biotech. 16:839-842.

Deising, H. B., Werner, S., and Wernitz, M. 2000. The role of fungal appressoria in plant infection. Microbes Infect. 2:1631-1641.

Dufresne, M., Bailey, J. A., Dron, M., and Langin, T. 1998. clk1, a serine/threonine protein kinase-encoding gene, is involved in pathogeicity of Colletotrichum lindemuthianum on common bean. Mol. PlantMicrobe Interact. 11:99-108.

Dufresne, M., Perfect, S., Pellier, A. L., Bailey, J. A., and Langin, I. 2000. A GAL4-like protein is involved in the switch between biotrophic and necrotrophic phases of the infection process of Colletotrichum lindemuthianum on common bean. Plant Cell 12:1579-1589.

Eisenhaber, B., Schneider, G., Wildpaner, M., and Eisenhaber, F. 2004. A sensitive predictor for potential GPI lipid modification sites in fungal protein sequences and its application to genome-wide studies for Aspergillus nidulans, Candida albicans, Neurospora crassa, Saccharomyces cerevisiae and Schizosaccharomyces pombe. J. Mol. Biol. 337:243-253.

Emanuelsson, O., Brunak, S., von Heijne, G., and Nielsen, H. 2007. Locating proteins in the cell using TargetP, SignalP and related tools. Nat. Protoc. 2:953-971.

Fernandez, M. R., and Heath, M. C. 1986. Cytological responses induced by five phytopathogenic fungi in a nonhost plant, Phaseolus vulgaris. Can. J. Bot. 64:648-657.

Flowers, J. L., and Vaillancourt, L. J. 2005. Parameters affecting the efficiency of Agrobacterium tumefaciens-mediated transformation of Colletotrichum graminicola. Curr. Genet. 48:380-388.

Guevara-Olvera, L., Xoconostle-Cazares, B., and Ruiz-Herrera, J. 1997. Cloning and disruption of the ornithine decarboxylase gene of Ustilago maydis: Evidence for a role of polyamines in its dimorphic transition. Microbiology 143:2237-2245.

Guisbert, K. S. K., Li, H., and Guthrie, C. 2007. Alternative 3' pre-mRNA processing in Saccharomyces cerevisiae is modulated by Nab4/Hrp1 in vivo. Plos Biol. 5:15-22.

Holm, S. 1979. A simple sequentially rejective multiple test procedure. Scand. J. Stat. 6:65-70.

Jeon, J., Park, S.-Y., Chi, M.-H., Choi, J., Park, J., Rho, H.-S., Kim, S., Goh, J., Yoo, S., Choi, J., Park, J.-Y., Yi, M., Yang, S., Kwon, M.-J., Han, S.-S., Kim, B. R., Khang, C. H., Park, B., Lim, S.-E., Jung, K., King, S., Karunakaran, M., Oh, H.-S., Kim, H., Kim, S., Park, J., Kang, S., Choi, W.-B., Kang, S., and Lee, Y.-H. 2007. Genome-wide functional analysis of pathogenicity genes in the rice blast fungus. Nature Genet. 39:561-565.

Kahmann, R., and Basse, C. 1999. REMI (restriction enzyme mediated integration) and its impact on the isolation of pathogenicity genes in fungi attacking plants. Eur. J. Plant Pathol. 105:221-229.

Kim, H., Ahn, J. H., Görlach, J. M., Caprari, C., Scott-Craig, J. S., and Walton, J. D. 2001. Mutational analysis of $\beta$-glucanase genes from the 
plant-pathogenic fungus Cochliobolus carbonum. Mol. Plant-Microbe Interact. 14:1436-1443.

Kimura, A., Takano, Y., Furusawa, I., and Okuno, T. 2001. Peroxisomal metabolic function is required for appressorium-mediated plant infection by Colletotrichum lagenarium. Plant Cell 13:1945-1957.

Kleemann, J., Takahara, H., Stuber, K., and O'Connell, R. 2008. Identification of soluble secreted proteins from appressoria of Colletotrichum higginsianum by analysis of expressed sequence tags. Microbiology. 154:1204-1217.

Lee, B. J., Cansizoglu, A. E., Suel, K. E., Louis, T. H., Zhang, Z., and Chook, Y. M. 2006. Rules for nuclear localization sequence recognition by karyopherin beta 2. Cell. 126:543-558.

Li, G., Zhou, W., Liu, G., Zheng, F., and C., H. 2007. Characterization of T-DNA insertion patterns in the genome of rice blast fungus Magnaporthe oryzae. Curr. Genet. 51:233-243.

Lipka, V., Dittgen, J., Bednarek, P., Bhat, R., Wiermer, M., Stein, M., Landtag, J., Brandt, W., Rosahl, S., Scheel, D., Llorente, F., Molina, A., Parker, J., Somerville, S., and Schulze-Lefert, P. 2005. Pre- and postinvasion defenses both contribute to nonhost resistance in Arabidopsis. Science. 310:1180-1183.

Liu, Y.-G., and Whittier, R. F. 1995. Thermal asymmetric interlaced PCR: Automatable amplification and sequencing of insert end fragments from P1 and YAC clones for chromosome walking. Genomics 25:674-681.

Martinez-Pacheco, M., Rodriguez, G., Reyna, G., Calvo-Mendez, C., and Ruiz-Herrera, J. 1989. Inhibition of the yeast-mycelial transition and the phorogenesis of Mucorales by diamino butanone. Arch. Microbiol. 151:10-14.

Maruthachalam, K., Nair, V., Rho, H. S., Choi, J., Kim, S., and Lee, Y. H. 2008. Agrobacterium tumefaciens-mediated transformation in Colletotrichum falcatum and C. acutatum. J Microbiol Biotechnol. 18:234-241.

Meng, Y., Patel, G., Heist, M., Betts, M. F., Tucker, S. L., Galadima, N., Donofrio, N. M., Brown, D., Mitchell, T. K., Li, L., Xu, J. R., Orbach, M., Thon, M., Dean, R. A., and Farman, M. L. 2007. A systematic analysis of T-DNA insertion events in Magnaporthe oryzae. Fungal Genet. Biol. 44:1050-64.

Michielse, C. B., Hooykaas, P. J. J., van den Hondel, C., and Ram, A. F. J 2005. Agrobacterium-mediated transformation as a tool for functional genomics in fungi. Curr. Genet. 48:1-17.

Morishita, R., Kawagoshi, A., Sawasaki, T., Madin, K., Ogasawara, T., Oka, T., and Endo, Y. 1999. Ribonuclease activity of rat liver perchloric acid-soluble protein, a potent inhibitor of protein synthesis. J. Biol. Chem. 274:20688-20692.

Mullins, E. D., Chen, X., Romaine, P., Raina, R., Geiser, D. M., and Kang, S. 2001. Agrobacterium-mediated transformation of Fusarium oxysporum: An efficient tool for insertional mutagenesis and gene transfer. Phytopathology 91:173-180.

Namiki, F., Matsunaga, M., Okuda, M., Inoue, I., Nishi, K., Fujita, Y., and Tsuge, T. 2001. Mutation of an arginine biosynthesis gene causes reduced pathogenicity in Fusarium oxysporum f. sp. melonis. Mol. PlantMicrobe Interact. 14:580-584.

Narusaka, Y., Narusaka, M., Park, P., Kubo, Y., Hirayama, T., Seki, M., Shiraishi, T., Ishida, J., Nakashima, M., Enju, A., Sakurai, T., Satou, M., Kobayashi, M., and Shinozaki, K. 2004. RCH1, a locus in Arabidopsis that confers resistance to the hemibiotrophic fungal pathogen Colletotrichum higginsianum. Mol. Plant-Microbe Interact. 17:749-762.

Nishimura, M. T., Stein, M., Hou, B.-H., Vogel, J. P., Edwards, H., and Somerville, S. C. 2003. Loss of a callose synthase results in salicylic acid-dependent disease resistance. Science. 301:969-972.

O'Connell, R. J., Herbert, C., Sreenivasaprasad, S., Khatib, M., EsquerreTugaye, M. T., and Dumas, B. 2004. A novel Arabidopsis-Colletotrichum pathosystem for the molecular dissection of plant-fungal interactions. Mol Plant-Microbe Interact. 17:272-282.

Ochman, H., Gerber, A. S., and Hartl, D. L. 1988. Genetic applications of an inverse polymerase chain reaction. Genetics 120:621-623.

Pellier, A. L., Lauge, R., Veneault-Fourrey, C., and Langin, T. 2003. CLNR1, the AREA/NIT2-like global nitrogen regulator of the plant fungal pathogen Colletotrichum lindemuthianum is required for the infection cycle. Mol. Microbiol. 48:635-655.

Perpetua, N. S., Kubo, Y., Yasuda, N., Takano, Y., and Furusawa, I. 1996. Cloning and characterization of a melanin biosynthetic THR1 reductase gene essential for appressorial penetration of Colletotrichum lagenarium. Mol. Plant-Microbe Interact. 9:323-329.

Seong, K., Hou, Z. M., Tracy, M., Kistler, H. C., Xu, J. R. 2005. Random insertional mutagenesis identifies genes associated with virulence in the wheat scab fungus Fusarium graminearum. Phytopathology 95:744-750.

Soanes, D. M., and Talbot, N. J. 2006. Comparative genomic analysis of phytopathogenic fungi using expressed sequence tag (EST) collections. Mol. Plant Pathol. 7:61-70.

Stein, M., Dittgen, J., Sanchez-Rodriguez, C., Hou, B. H., Molina, A., Schulze-Lefert, P., Lipka, V., and Somerville, S. 2006. Arabidopsis PEN3/PDR8, an ATP binding cassette transporter, contributes to nonhost resistance to inappropriate pathogens that enter by direct penetration. Plant Cell. 18:731-746.

Stephenson, S.-A., Hatfield, J., Rusu, A. G., Maclean, D. J., and Manners, J. M. 2000. CgDN3: An essential pathogenicity gene of Colletotrichum gloeosporioides necessary to avert a hypersensitive-like response in the host Stylosanthes guianensis. Mol Plant-Microbe Interact. 13:929-941.

Sweigard, J. A., Carroll, A. M., Farrall, L., Chumley, F. G., and Valent, B. 1998. Magnaporthe grisea pathogenicity mutants obtained through insertional mutagenesis. Mol. Plant-Microbe Interact. 11:404-412.

Takahara, H., Tsuji, G., Kubo, Y., Yamamoto, M., Toyoda, K., Inagaki, Y., Ichinose, Y., and Shiraishi, T. 2004. Agrobacterium tumefaciens mediated transformation as a tool for random mutagenesis of Colletotrichum trifolii. J. Gen. Plant Pathol. 70:93-96.

Takano, Y., Kubo, Y., Shimizu, K., Mise, K., Okuno, T., and Furusawa, I. 1995. Structural analysis of $p k s 1$, a polyketide synthase gene involved in melanin biosynthesis in Colletotrichum lagenarium. Mol. Gen. Genet. 249:162-167.

Talhinhas, P., Muthumeenakshi, S., Neves-Martins, J., Oliveira, H., and Sreenivasaprasad, S. 2008. Agrobacterium-mediated transformation and insertional mutagenesis in Colletotrichum acutatum for investigating varied pathogenicity lifestyles. Mol. Biotechnol. 39:57-67.

Tanaka, S., Yamada, K., Yabumoto, K., O’Connell, R., Tsuji, G., Koga, H., Dohi, K., Mori, M., Shiraishi, T., and Kubo, Y. 2007. Saccharomyces cerevisiae SSD1 orthologues are essential for host infection by the ascomycete plant pathogens Colletotrichum lagenarium and Magnaporthe grisea. Mol. Microbiol. 64:1332-1349.

Tang, W., Coughlan, S., Crane, E., Beatty, M., and Duvick, J. 2006. The application of laser microdissection to in planta gene expression profiling of the maize anthracnose stalk rot fungus Colletotrichum graminicola. Mol. Plant-Microbe Interact. 19:1240-1250.

Thon, M. R., Nuckles, E. M., Takach, J. E. and Vaillancourt, L. J. 2002. CPR1: A gene encoding a putative signal peptidase that functions in pathogenicity of Colletotrichum graminicola to maize. Mol. PlantMicrobe Interact. 15:120-128.

Thon, M. R., Nuckles, E. M., and Vaillancourt, L. J. 2000. Restriction enzyme-mediated integration used to produce pathogenicity mutants of Colletotrichum graminicola. Mol. Plant-Microbe Interact. 12:1356-1365.

Thordal-Christensen, H., Zhang, Z., Wei, Y. D., and Collinge, D. B. 1997. Subcellular localization of $\mathrm{H}_{2} \mathrm{O}_{2}$ in plants. $\mathrm{H}_{2} \mathrm{O}_{2}$ accumulation in papillae and hypersensitive response during the barley-powdery mildew interaction. Plant J. 11 1187-1194.

Tsuji, G., Fujii, S., Fujihara, N., Hirose, C., Tsuge, S., Shiraishi, T., and Kubo, Y. 2003. Agrobacterium tumefaciens-mediated transformation for random insertional mutagenesis in Colletotrichum lagenarium. J. Gen. Plant Pathol. 69:230-239.

Walton, F. J., Idnurm, A., and Heitman, J. 2005. Novel functions required for melanization of the human pathogen Cryptococcus neoformans Mol. Microbiol. 57:1381-1386.

Weld, R. J., Plummer, K. M., Carpenter, M. A., and Ridgway, H. J. 2006. Approaches to functional genomics in filamentous fungi. Cell Res. 16:31-44.

Zhang, J., Guo, D., Chang, Y., You, C., Li, X., Dai, X., Weng, Q., Zhang, J., Chen, G., Li, X., Liu, H., Han, B., Zhang, Q., and Wu, C. 2007. Nonrandom distribution of T-DNA insertions at various levels of the genome hierarchy as revealed by analyzing 13804 T-DNA flanking sequences from an enhancer-trap mutant library. Plant J. 49:947-59.

\section{AUTHOR-RECOMMENDED INTERNET RESOURCES}

ATMT database: atmt.snu.ac.kr/

Big-PI fungal predictor: mendel.imp.ac.at/gpi/fungi_server.html InterProScan server: www.ebi.ac.uk/Tools/InterProScan NCBI website: www.ncbi.nlm.nih.gov

Pathogen-Host Interactions database (PHI-base): www.phi-base.org Softberry gene prediction tools: linux 1.softberry.com/berry.phtm Signal P server: www.cbs.dtu.dk/services/SignalP TMHMM server: www.cbs.dtu.dk/services/TMHMM 